\title{
$\alpha$-Tocopherol Protects Against Oxidative Stress in the Fragile $X$ Knockout Mouse: an Experimental Therapeutic Approach for the Fmrl Deficiency
}

\author{
Yolanda de Diego-Otero*,', Yanina Romero-Zerbo', Rajaa el Bekay',2, Juan Decara', Lourdes Sanchez', \\ Fernando Rodriguez-de Fonseca' and Ignacio del Arco-Herrera ${ }^{1,3}$ \\ 'Fundacion IMABIS, Hospital Carlos Haya, Malaga, Spain; ${ }^{2}$ CIBER Fisiopatologia Obesidad y Nutricion (CB06/03), Instituto de Salud Carlos III, \\ Spain; ${ }^{3}$ Instituto de Innovación para el Bienestar Ciudadano, Parque Tecnologico de Andalucia, Malaga, Spain
}

\begin{abstract}
Fragile $X$ syndrome is the most common genetic cause of mental disability. The mechanisms underlying the pathogenesis remain unclear and specific treatments are still under development. Previous studies have proposed an abnormal hypothalamic-pituitary-adrenal axis and high cortisol levels are demonstrated in the fragile $X$ patients. Additionally, we have previously described that NADPH-oxidase activation leads to oxidative stress in the brain, representing a pathological mechanism in the fragile $X$ mouse model. Fmrl-knockout mice develop an altered free radical production, abnormal glutathione homeostasis, high lipid and protein oxidation, accompanied by stressdependent behavioral abnormalities and pathological changes in the first months of postnatal life. Chronic pharmacological treatment with $\alpha$-tocopherol reversed pathophysiological hallmarks including free radical overproduction, oxidative stress, Racl and $\alpha$-PKC activation, macroorchidism, and also behavior and learning deficits. The restoration of the oxidative status in the fragile $X$ mouse emerges as a new and promising approach for further therapeutic research in fragile $X$ syndrome.

Neuropsychopharmacology (2009) 34, I0I I-1026; doi:I0.1038/npp.2008. I52; published online 8 October 2008
\end{abstract}

Keywords: Fragile $X$ syndrome; Fmrl knockout; oxidative stress; tocopherol; Racl; therapeutic target

\section{INTRODUCTION}

The fragile $\mathrm{X}$ syndrome is the most common form of inherited mental retardation. The prevalence of the full mutation ranges from 1 of 2500 to 1 of 6000 males, and 1 of 4000 to 1 of 8000 females in the general population (Hagerman and Hagerman, 2001). Instability of CGG repeats in the FMR1 (fragile X mental retardation 1) gene is the most frequent mutation, and the absence of FMRP protein (FMR1 gene functional product) is responsible for the phenotype (Verkerk et al, 1991). In addition to mental retardation, patients exhibit macroorchidism, elongated faces, connective tissue dysplasia, hyperactivity, autism and stereotype behaviors, and increased sensory sensitivity (Bardoni et al, 2006; Frankland et al, 2004).

In the brain, FMRP is highly expressed in neurons, it is associated with translating ribosomes in the cytoplasm, and is localized in dendrites and dendritic spines (De Diego Otero et al, 2002; Weiler et al, 1997). FMRP is densely

\footnotetext{
* Correspondence: Dr Y de Diego Otero, Fundacion IMABIS, Hospital Carlos Haya, Laboratorio de Investigacion, Hospital Civil, Pabellon 5-Sot, 2901 I Malaga, Spain, Tel: + 3495 1290346, Fax: + 34951290302 , E-mail: yolanda.diego.exts@juntadeandalucia.es

Received 18 February 2008; revised 31 July 2008; accepted 19 August 2008
}

expressed in the mouse adrenal medulla, without coexpression of both homologous fragile X-related proteins, FXR1P and FXR2P; therefore, FMRP may have a specific function in this tissue (De Diego Otero et al, 2000). It has been proposed that FMRP acts as a translational repressor of a subset of neuronal mRNAs, and may be involved in synaptic mRNA localization, as it is present in mRNP localization complexes (Zalfa et al, 2007).

The Fmr1-knockout (Fmr1-KO) mouse develops macroorchidism and sensory hyperreactivity to auditory stimuli. It has significantly less freezing behavior, altered synaptic plasticity, learning deficits and hyperactivity, as well as brain glucose hypermetabolism. Consequently, the Fmr1KO mouse phenotype is comparable to the patient phenotype and may serve as a valuable tool to study the physiological roles of FMRP and the mechanisms involved in the pathology of the syndrome (Bakker et al, 1994).

Fragile $\mathrm{X}$ patients display an increase in adrenocortical activity and an altered hypothalamic-pituitary-adrenal (HPA) axis (Hessl et al, 2002). Adrenal hormones have been involved in the induction of brain oxidative stress resulting in oxidation of molecules and depletion of antioxidants such as glutathione (GSH) (Herman and Cullinan, 1997). Oxidative stress results from an imbalance between the formation and neutralization of pro-oxidants and leads to the dysregulation of the cellular physiology. 
Sources of endogenous-free radicals are oxygenase and oxidase activities, catecholamines, glucocorticoids, and mitochondrial energy production. Oxidative stress may perturb presynaptic plasticity in the brain, with long-lasting effects such as damage to neurons in areas of the brain implicated in learning, memory, and emotional homeostasis such as hippocampus, amygdala, and cortex (Virgin et al, 1991; Weber 1999). Inadequate regulation of stress responses and oxidative stress are implicated in the pathogenesis of systemic and neurodegenerative diseases, and can be observed in Down's syndrome and autism (Iannello et al, 1999; Chauhan and Chauhan, 2006). Our previous studies have linked the increased generation of reactive oxygen species (ROS), NADPH-oxidase activation, and the moderate increase of brain oxidative stress, as key pathological components in the mouse model of fragile $\mathrm{X}$ syndrome (el Bekay et al, 2007).

Although there are multiple ROS sources in the brain, NADPH oxidase is one of the most important enzymes. It catalyzes the reduction of molecular oxygen to form superoxide $\left(\mathrm{O}^{2-}\right)$, a potent-free radical that has a physiological function in the nervous system. NADPH-oxidase enzyme activity is regulated by four cytosolic subunits: $\mathrm{p} 47^{\text {phox }}, \mathrm{p} 67^{\text {phox }}, \mathrm{p} 40^{\text {phox }}$, and small Rac-GTPase proteins (Wautier et al, 2001). A major concept in redox signaling is that although NADPH-oxidase-derived ROS are necessary for normal cellular function, excessive production leads to oxidative stress and can contribute to pathological diseases. This is certainly true in the central nervous system, where normal NADPH oxidase appears to be required for neuronal signaling, memory, and central cardiovascular homeostasis; however, overproduction of ROS contributes to neurotoxicity, neurodegeneration, and cardiovascular diseases (Lambeth, 2004).

There has been considerable interest in the potential role of $\alpha$-tocopherol in the treatment of oxidative stressmediated diseases, such as Alzheimer's disease (Sano et al, 1997; Morris et al, 2002) or Parkinson's (Fariss and Zhang, 2003). $\alpha$-Tocopherol has the highest biological activity as an antioxidant/radical scavenger (Osakada et al, 2003); however, recent studies revealed non-antioxidant neuroprotective effects, for example, reduction of PKC- $\alpha$ activity through dephosphorylation (Zingg and Azzi, 2004).

There has also been extensive interest in $\mathrm{N}$-acetyl-Lcysteine (NAC); it provides an alternate means of boosting intracellular GSH via elevated intracellular cysteine. GSH is the predominant antioxidant in the aqueous cytoplasm of cells, and virtually all cells require GSH for viability and function. GSH can scavenge peroxynitrite and hydroxyl radicals as well as convert hydrogen peroxide into water. NAC can rescue neurons from apoptotic death through direct action on transcription factors by the thiol group, rather than by antioxidant effects (Yan and Greene, 1998).

Although the most frequent symptoms have limited relief with psychopharmacological treatments (Chiurazzi et al, 2003), there are numerous researches investigating treatments for the syndrome. The fragile $\mathrm{X}$ mutation produces a highly selective impairment to long-term potentiation (LTP) and the infusion of the neurotrophin, BDNF, fully restored LTP in slices from the fragile X mice (Lauterborn et al, 2007). A partial reversion of the characteristics observed in the animal model for fragile $\mathrm{X}$ syndrome has been demonstrated using glutamate receptor antagonist drugs (McBride et al, 2005; Yan et al, 2005). Recently, two published studies have demonstrated that the fragile $\mathrm{X}$ phenotype can be normalized by generating a double $\mathrm{KO}$ of the Fmr1 gene and the mGlur5 gene (Dölen et al, 2007), or by generating a double $\mathrm{KO}$ of the Fmr1 gene and the p21activated kinase (PAK) gene (Hayashi, 2007). It has already been demonstrated that gene therapy failed to completely normalize the Fmr1-KO model (Peier et al, 2000).

In the present study, we demonstrate for the first time that chronic $\alpha$-tocopherol treatment reverses several biochemical hallmarks described in the Fmr1-KO mouse, such as Rac1-GTPase and $\alpha$-PKC inactivation, free radical production and oxidative stress, although it also normalizes many of the behavioral and learning deficits. On the other hand, treatment with NAC, a precursor of GSH acting as a free radical scavenger, produced weaker effects.

\section{MATERIALS AND METHODS}

\section{Animal Model}

We used the Fmr1-KO FVB-129 mouse line obtained as a gift from B. Oostra (Erasmus University Rotterdam) (Bakker et al, 1994). All experimental protocols met the guidelines of the Animal Welfare Committee of the University of Malaga and the European Communities Council Directive (86/609/EEC) and current Spanish legislation for the use and care of laboratory animals (BOE 252/ 34367-91, 2005). The mice were kept as a colony, housed under controlled conditions of temperature and humidity, with a $12 \mathrm{~h}$ light/dark cycle and free access to standard food and water. Wild-type (WT) and Fmr1-KO male mouse littermates were used for all the experiments and were obtained from crossing heterozygous $\left(\mathrm{X}_{\mathrm{WT}} / \mathrm{X}_{F m r 1}\right.$ ко $)$ females and hemizygous $\left(\mathrm{X}_{F m r 1} \mathrm{kO} / \mathrm{Y}\right)$ males, and randomly located in different experimental groups. We ran the experiments on 205 male mice aged $60-180$ days (8-12 mice per each experimental group).

Male control animals (nonstressed naïve and vehicle) were housed 3-4 animals per cage and handled daily. The chronic social stressed groups were achieved by housing nonhandled animals 10-12 in a large cage for the duration of the experimental protocol. Male acute stress groups were exposed once to acute stress by immobilization in an exclusive room at the animal house, by placing individual animals in a restrain mouse container attached to a wooden board. The experimental mice were deprived of food and water during acute stress exposure (Singh et al, 1993). Animals were subjected to stress for $15 \mathrm{~min}$, and then immediately used to analyze behavior. After the behavior studies, blood samples were taken by retro-orbital puncture, to measure the corticosterone and catecholamine levels in plasma.

\section{Genotype Analysis}

Tail DNA was isolated to analyze the genotype of the mice. PCR analysis was used with a pair of primers described previously by Bakker et al (1994). Briefly, diluted DNA $(2 \mu \mathrm{l})$ and 5 pmol of appropriate primers were used with the 
Ready Mix Kit (Sigma Chemical Co., St Louis, MO). The PCR reactions were carried out on a thermocycler (PerkinElmer, Fremont, CA) and the products (Fmr1-KO allele of $800 \mathrm{bp}$ and WT allele of $465 \mathrm{bp}$ ) were visualized by ethidium bromide on a $1.5 \%$ agarose gel electrophoresis.

\section{Drugs and Reagents}

Acetate DL- $\alpha$-tocopherol (TOC) was obtained from Roche Diagnostic (Indianapolis, Indiana). NAC was obtained from Zambon SA (Barcelona Spain). Reagents were obtained from Sigma Chemical Co. Rabbit polyclonal antiRac1 (sc-217), goat polyclonal anti-phospho-specific PKC- $\alpha$ (sc-12356) and rabbit polyclonal anti-PKC- $\alpha$ (sc-208), antibodies were purchased from Santa Cruz Biotechnology Inc. (Santa Cruz, CA). HRP-labeled anti-rabbit IgG was purchased from Amersham International (Buckinghamshire, UK). PAK-1 p21-binding domain was purchased from Upstate Cell Signaling (Charlottesville, VA).

\section{Treatments}

Treatment was initiated at 3 months of age. The mice were divided into trial groups: controls, TOC-treated groups, NACtreated groups, and NAC plus TOC (TOC+NAC)-treated groups. Mice receiving treatment were injected intraperitoneally (i.p.) daily (for NAC) or every second day (for $\alpha$ tocopherol). We first performed a dose-response trial and second, a time-course trial for treatment with $\alpha$-tocopherol acetate. Moreover, a third trial was performed with one dosage of NAC. And finally, a fourth trial was performed using a combination of $\alpha$-tocopherol acetate plus NAC. These trials were compared to naïve and vehicle groups.

\section{Animal Groups}

Daily handled: (1) naïve, (2) acute stressed by immobilization, (3) social stressed. Chronic treatment, 30-day trial: (4) vehicle: normal saline $(1 \mathrm{ml} / \mathrm{kg})$ was injected i.p. to the control groups as a vehicle. (5) $\alpha$-tocopherol (50 mg/kg), (6) $\alpha$-tocopherol (100 mg/kg), (7) NAC (200 mg/kg), (8) $\alpha$ tocopherol $(100 \mathrm{mg} / \mathrm{kg})$ were combined to $200 \mathrm{mg} / \mathrm{kg}$ NAC. Acute treatment, 10 -day trial: (9) $\alpha$-tocopherol $(100 \mathrm{mg} / \mathrm{kg})$ was administered every 2 days.

\section{Behavioral Study}

We examined naïve condition groups to study basal responses in the open-field and the elevated plus maze (Lister, 1987), compared with acute stressed groups, social stressed groups, and treated groups. The habituation profile was characterized by the exposure to the open-field paradigm, in novelty and familiarity (ie $24 \mathrm{~h}$ later) both in basal conditions and after treatment. The open field apparatus and testing procedures were similar to those used previously by Crusio and Schwegler (1987). The animals were placed in the test room $30 \mathrm{~min}$ prior to the experiments. For the fear conditioning paradigm the mice were studied under basal conditions (naïve) and after treatment in the Shuttle-box maze (Phillips and LeDoux, 1992) (see Supplementary Materials and Methods for specific details).

\section{Preparation of Peritoneal Macrophages}

Peritoneal macrophages were isolated from mice and kept under standard conditions. The animals $(30-35 \mathrm{~g})$ were killed by cervical dislocation, and peritoneal macrophages were extracted by i.p. saline injection of $5 \mathrm{ml}$. The cells were pelleted by centrifugation, suspended in HEPES-buffered Krebs-Ringer solution (KR-HEPES), composed of $118 \mathrm{mM}$ $\mathrm{NaCl}, 4.75 \mathrm{mM} \mathrm{KCl}, 1.18 \mathrm{mM} \mathrm{H} \mathrm{H}_{2} \mathrm{PO}_{4}, 1.18 \mathrm{mM} \mathrm{MgSO}_{4}$, $1.25 \mathrm{mM} \mathrm{CaCl}, 10 \mathrm{mM}$ glucose, and $25 \mathrm{mM}$ HEPES $(\mathrm{pH}$ 7.4) and used immediately for experiments.

\section{Intracellular $\mathrm{H}_{2} \mathrm{O}_{2}$ Production}

The production of ROS was analyzed by 2,7-dichlorodihydrofluorescein diacetate (DCFDA), as an indicator of the quantity of intracellular $\mathrm{H}_{2} \mathrm{O}_{2}$. Briefly, $2 \times 10^{6}$ (cells per ml) macrophages were incubated at $37^{\circ} \mathrm{C}$ in the dark in the presence of $2.5 \mu \mathrm{M}$ DCFDA (dissolved in ethanol). The cells were then rinsed twice with KR-HEPES buffer, and the fluorescence intensity was measured at different times in a spectrofluorometer using excitation and emission wavelengths of 503 and $529 \mathrm{~nm}$, respectively, with a Clarity Microplate Reader (Biotek, Vermont, USA). The final values were corrected for intracellular protein in each well and expressed as a percent of fluorescence in control wells.

\section{Brain Dissection}

Animals were killed by cervical dislocation. The brains were removed immediately at $4^{\circ} \mathrm{C}$. For ex-vivo experiments, brain tissue was sectioned into $100-\mu \mathrm{m}$-thick slices and transferred onto plates containing sterile KR-HEPES buffer for ROS assays.

\section{Measurement of Total Reactive Oxygen Species Production}

Luminol-based luminescence correlated well with total ROS produced by the cells. As luminol can permeate freely through the cell membrane, luminescence was an indication of the addition of intracellular plus extracellular ROS ( $\mathrm{Li}$ et al, 1998). Briefly, brain slices were suspended in KRHEPES, and $15 \mu \mathrm{M}$ luminol was added. The reaction was started by the addition of $100 \mathrm{nM}$ phorbol 12 -myristate 13acetate (PMA), and the chemiluminescence emission was recorded. Total ROS production was measured in brain slices at basal levels and after in vitro $40 \mu \mathrm{M} \alpha$-tocopherol incubation for $24 \mathrm{~h}$ at $37^{\circ} \mathrm{C}$ and $5 \% \mathrm{CO}_{2}$.

\section{Determination of Thiobarbituric Acid- Reactive Substances}

Measurement of malondialdehyde (MDA), the most abundant product arising from lipid peroxidation, has been extensively used as an index of oxidative stress. We determined MDA by quantifying thiobarbituric acid-reactive substances (TBARS) by spectrophotometry (Esterbauer and Cheeseman, 1990). Absorbance was determined spectrophotometrically at a wavelength of $532 \mathrm{~nm}$ (VERSAmax spectrophotometer, Molecular Device, USA). The protein concentration was determined with the Bradford method 
(Bradford, 1976) (see Supplementary Materials and Methods for further details).

\section{Antioxidant Assay}

Measurement of both reduced GSH and glutathione disulfide (GSSG) in tissue has been considered essential as an index of the antioxidant GSH status and a useful indicator of oxidative stress status in a tissue. A characteristic hallmark of many pathophysiologic conditions is a decrease in the GSH/GSSG ratio. GSH levels were measured by spectrofluorometry (Hissin and Hilf, 1976) (see Supplementary Materials and Methods for further details).

\section{Enzymatic Assays}

Glutathione peroxidase (GSHpx), glutathione reductase (GSSGrd), and GSH transferase (GSHtf) were determined by spectrophotometric kinetics. GSSGrd was assayed following NADPH oxidation at $340 \mathrm{~nm}$ (Carlberg and Mannervik, 1985). GSH peroxidase was determined according to Flohé and Gunzler (1984), with tert-butyl hydroperoxide as substrate. GSHtf was determined according to previous literature (Warholm et al, 1985), using 1-chloro-2,4-dinitrobenzene as a substrate (see Supplementary Materials and Methods for further details).

\section{Protein Assays}

The formation of carbonyl compounds is actually the most general and widely used marker of severe protein oxidation both in vitro and in vivo. As a marker of oxidative damage to proteins, carbonyl contents have been shown to accumulate during aging, chronic inflammation, and many age-related diseases in a variety of organisms (Dalle-Donne et al, 2003; Dean et al, 1997). To analyze protein oxidation, we followed the method described previously by Levine (2002) (see Supplementary Materials and Methods for further details).

\section{Hormonal Assays}

Plasma and adrenal catecholamines were measured by HPLC coupled to electrochemical detection (del Arco et al, 2000). We assayed plasma corticosterone and testosterone concentrations using commercially available $\mathrm{I}^{125}$-radioimmunoassay kits from ICN Pharmaceuticals, (Orangeburg, New York).

\section{Rac1 GTP-Binding Activity}

Racl activity pull-down assays were carried out, on the basis of the capability of PAK proteins to bind to GTPactivated Racl but not inactivated-Racl bound to GDP (see Supplementary Materials and Methods for further details).

\section{Western Blotting Analysis of Total-Rac1}

Protein $(20 \mu \mathrm{g})$ from the brains of three different animals were used on $8 \%$ SDS-PAGE electrophoresis. Rac1 rabbit polyclonal $(1: 800)$ and subsequently HRP-labeled anti- rabbit IgG $(1: 1200)$ were applied. Immunoreactivity for proteins was visualized by enhanced chemiluminescence. Relative intensity from each band was calculated from the Western blotting assays using 1D Manager2.0 (TDIS.A. Spain).

\section{PKC- $\alpha$ Activation}

Brain tissue was homogenized by sonication in a lysis buffer $(20 \mathrm{~W}$, three $5 \mathrm{~s}$ bursts each separated by $30 \mathrm{~s}$ intervals). The debris was removed by centrifugation at $10000 \mathrm{~g}$ for $5 \mathrm{~min}$ at $4{ }^{\circ} \mathrm{C}$. The supernatant $(80 \mu \mathrm{g})$ was incubated with $1 \mathrm{mg}$ of anti-PKC- $\alpha$ for $2 \mathrm{~h}$ at $4{ }^{\circ} \mathrm{C}$, then $40 \mu \mathrm{l}$ of A-Sepharose protein was added, and the precipitation of PKC- $\alpha$-antibody complex was carried out at $4{ }^{\circ} \mathrm{C}$ for $2 \mathrm{~h}$. The mixture was centrifuged at $10000 \mathrm{~g}$ for $5 \mathrm{~min}$, and the pellet was resuspended with the sample buffer. After centrifugation, the supernatant was subjected to SDS-PAGE and immunodetected with goat anti-phospho-PKC- $\alpha$ IgG, at $1: 2000$ dilution in PBS supplemented with $0.02 \%$ Tween 20 and $1 \%$ BSA, then incubated with HRP-conjugated anti-rabbit IgG at $1: 20000$ dilution in PBS with $0.5 \%$ BSA, followed by enhanced chemiluminescence. The membrane was stripped and then incubated with rabbit anti-cPKC- $\alpha$ and rabbit polyclonal IgG to assay the total $\alpha$-PKC $(1: 800$; Santa Cruz Biotechnology).

\section{Statistical Analysis}

The data in the text, tables, and figures are expressed as the mean \pm standard error of the mean from 4 to 12 experiments in samples from different animals. All statistical analyses were carried out with the Social Program for Statistical Sciences (SPSS v. 10.0) software program. The statistical significance of intergroup differences was evaluated by the two-tailed unpaired Student's $T$-test, with a significance level of $P<0.05$. Comparisons among multiple groups or repeated measurements were made by analysis of variance (ANOVA) followed by Bonferroni transformation and differences were established at $P<0.05$.

\section{RESULTS}

Fmr1-KO mice were studied for environmental stressdependent phenotypic and behavioral alterations. The changes reported here included increased organ weight, membrane protein content, altered glucocorticoid levels, activation of Rac 1 and $\alpha$-PKC proteins, as well as behavioral reactivity to acute and social stress. Interestingly, $\alpha$ tocopherol treatment reversed most of the pathological hallmarks indicated above.

\section{Fmr1-Knockout Mice Displayed Phenotypic Abnormalities and Stress-Dependent Behavioral Alterations}

Fmr1-KO mice showed increased weight of the salivary glands and pancreas in addition to macroorchidism already described by many reports (Supplementary Table S1), whereas the size of the brain, liver, spleen, and kidneys were normal compared to the WT-control group. Also a significant increased in body weight was found in 6-month- 
old Fmr1-KO mice in comparison to WT littermates (Supplementary Table S1). Pathological alteration of the testes was not associated with changes in testosterone levels (Fmrl-KO mice: $4.09 \pm 2.1 \mathrm{ng} / \mathrm{ml}$, and WT-control mice: $2.55 \pm 1.5 \mathrm{ng} / \mathrm{ml}$ of testosterone in plasma).

Studies using Fmr1-KO mice often resulted in contradictory data, especially in behavioral outcomes. In an attempt to systematize all the studies, we first performed a stress-dependent analysis of behavioral alterations. We performed the open-field and the elevated P-maze in young adult Fmr1-KO mice (4-month old). Open field was performed to characterize the basal level (naïve) of exploratory behavior (hyperactivity) in animals habituated to daily handling under novelty and familiar conditions. Fmr1-KO mice displayed an increase in total distance traveled, a well-known parameter for hyperactivity (Figure 1a), in comparison to the WT-control groups $(P<0.01, n=12-14)$. If the test was performed in animal groups under acute stress conditions, the Fmr1-KO mice reduced the total distance traveled and did not display a significant difference in novelty compared to the WT-control group, but there was a significant difference in familiarity, the WT-control mice showed habituation in contrast to the Fmr1-KO that did not display the expected habituation profile. When the mice were exposed to a social stress condition, the differences in total distance traveled were increased between genotypes in novelty and familiarity. In this specific behavioral paradigm, the WTcontrol mice showed a learning process where as KOs did not, it was observed in the second day of the trial that the exploratory behavior is reduced in WT-control group demonstrating habituation to the open field. However the Fmr1-KO mice showed approximately similar locomotor activity in novelty and familiarity, indicating an absence of habituation to the open field as an example of a learning deficit.

In the elevated P-maze, basal nonstressed Fmr1-KO mice (Naïve group) displayed an increase of the percentage of time spent in the exposed arms, reflecting lower anxiety than the WT-control group. Exposure to acute stress, by immobilization in nonhabituated animals, markedly reduced the percentage of time spent in the exposed arms in Fmr1-KO mice and the anxiety measurement is similar to WT-control that is also reduced in comparison to naïve groups, suggesting an enhanced reactivity to the aversive properties of the maze in both genotypes, it indicated increased anxiety under acute stress condition (Figure $1 \mathrm{~b}$ ). The social-stress Fmrl-KO group spent more time in the exposed arms of the P-maze compared to the WT-control group in the same conditions, indicating lower anxiety in the Fmr1-KO group; surprisingly similar results were formerly observed in naïve conditions.

To further characterize these context-dependent responses, we had measured the corticoadrenal response to stress. Fmr1-KO mice displayed lower corticosterone plasma levels when measured in naïve nonstressed animals (Figure 1c). The corticosterone levels were increased after exposure to acute stress in Fmrl-KO mice in comparison to the WT-control group. However, the chronic social stress Fmr1-KO group showed lower corticosterone levels, in comparison to the WT-control group, similar results were observed in naïve conditions.
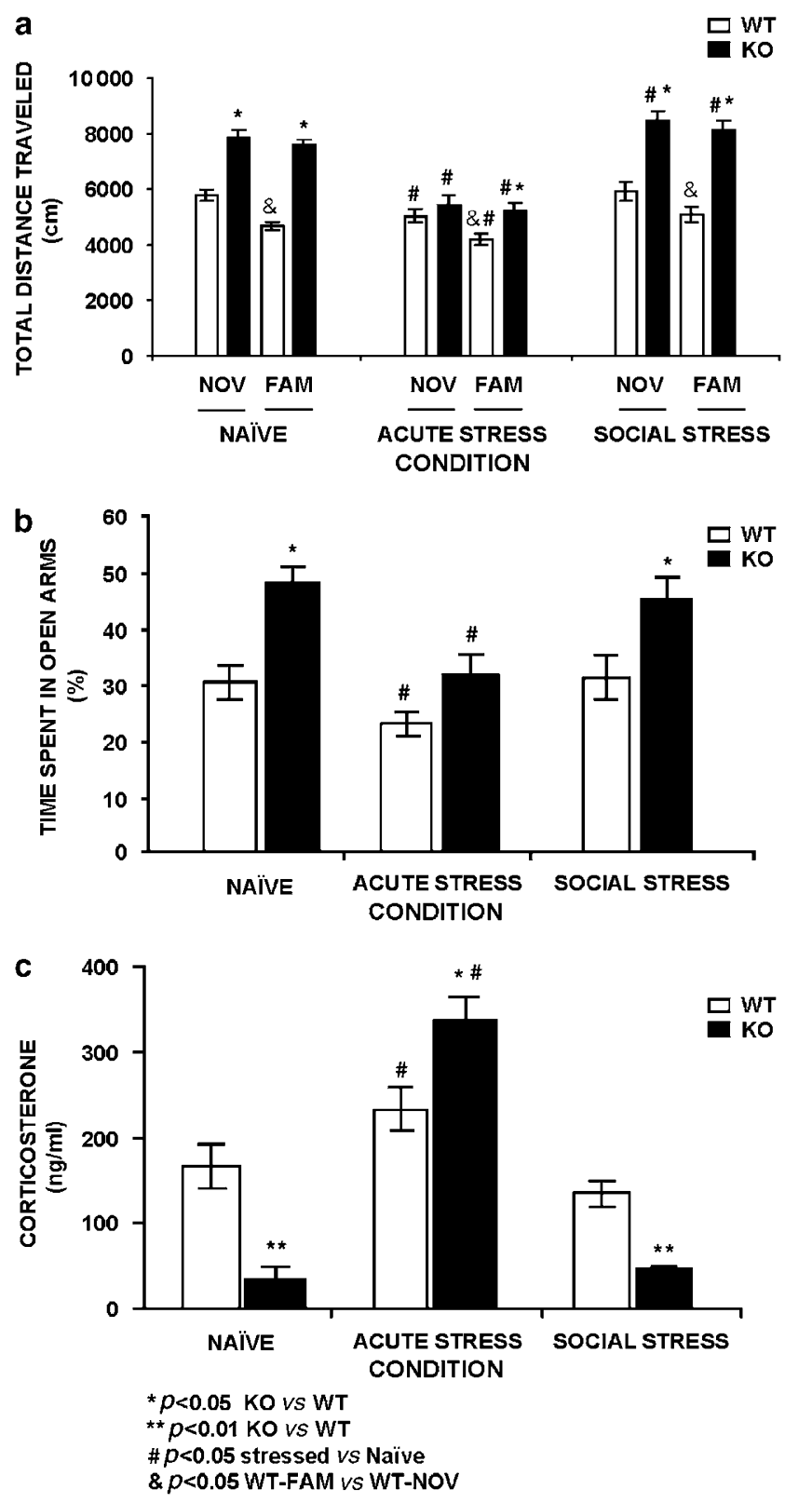

Figure I Selected stress-related phenotypic alterations of the Fmrlknockout $(K O)$ mice in comparison to wild-type (WT) littermate-controls. (a) Fmrl-KO mice display hyperactivity in novelty (NOV) and familiar (FAM) environments. The increased exploratory behavior observed in naive conditions is almost normal in the acute stress Fmrl-KO group in comparison to WT-control groups and those naïve groups. The social stress conditions enhanced the differences between genotypes. (b) Fmrl$\mathrm{KO}$ mice display anxiolysis in the P-maze under nonstressing conditions or under chronic social stress, but reduce significantly the percentage of time spent in the exposed arms during acute stress conditions. (c) Fmrl-KO mice had lower plasma corticosterone levels in basal nonstressing and social stressing conditions, but enhanced reactivity to acute stress (30 min restrain). Data are means \pm SEM of at least eight mice per group. Statistical analysis was done by unpaired T-test. $* P<0.05$ or $* * P<0.0$ I Fmrl-KO vs WT-control. ${ }^{\#} P<0.05$ stressed vs naïve. ${ }^{\&} p<0.05$ FAM-WT vs NOV-WT.

Fmr1-Knockout Mice Displayed Age- and Tissue-Dependent Enhanced Oxidative Stress

Fmr1-KO mice exhibited an early onset increase of oxidative stress in organs expressing FMRP such as brain 
and testicles. Oxidative stress was also found in salivary glands and the pancreas but not in the liver or kidneys (Supplementary Table S2). This is revealed by a decreased level in reduced GSH and an increase in oxidized GSH (GSSG). The activity of GSHtf and GSHpx, the main enzymes involved in GSH homeostasis were also decreased in brain, salivary glands, and testicles in young adult animals. To better characterize the oxidative stress status, a lipid peroxidation marker, represented by TBARS was measured in this study. The Fmr1-KO group showed increased levels of TBARS in cell membranes obtained from brain, testes, pancreas, and salivary glands, whereas the TBARS levels in kidneys and the liver were unchanged in comparison to the WT-control group. These changes were age-dependent, being present along the first months of postnatal life (Supplementary Table S2). Differences observed in oxidative stress parameters were not observed in older animals (6 months age), and it may be related to an enhanced oxidative stress that is normally associated to aging (Dalle-Donne et al, 2003; Dean et al, 1997). On the basis of these findings, we selected a time window of 60-120 days of postnatal life (young adult mice) for the characterization of treatment effectiveness on phenotypic alterations associated with FMRP absence.

\section{$\alpha$-Tocopherol Reversed Physical Body Abnormalities and Oxidative Stress Markers in a Dose-Dependent Manner in Fmr1 Knockout}

To evaluate the effectiveness of an antioxidant neuroprotective therapy to normalize the Fmr1-KO mouse phenotype, we performed treatment trials with $\alpha$-tocopherol acetate (Supplementary Figure S1a) and NAC (Supplementary Figure S1b). Chronic (i.p.) treatment with $100 \mathrm{mg} / \mathrm{kg} \alpha-$ tocopherol every second day during 30 days was sufficient to normalize the body organ weights altered in the vehicle Fmr1-KO group, such as testicles $(\mathrm{F}=16.53, \mathrm{df}=1$, $p<0.0002, \%$ of total variation 23.77), salivary glands ( $\mathrm{F}=15.31, \mathrm{df}=1, P<0.0003, \%$ of total variation 21.85$)$, and pancreas $(\mathrm{F}=10.23, \mathrm{df}=1, P<0.002, \%$ of total variation 16.81) (Supplementary Table S3).

Free radical production was measured in macrophage cells (Figure 2a) and brain slices (Figure 2b). A significant increase in free radical production was observed in macrophage cells and brain slices in Fmrl-KO mice in comparison to the WT-control mice in presence of $100 \mathrm{nM}$ WT-PMA. The in vitro treatment with $40 \mu \mathrm{M} \alpha$-tocopherol for $24 \mathrm{~h}$ reduced significantly endogen-free radical production to WT-control levels in macrophage cells; it was analyzed by repeated measurement comparisons (ANOVA) of tocopherol-treated group $v s$ basal groups, $(\mathrm{F}=35800$, $\mathrm{df}=3, p<0.0001, \%$ of total variation 80.5 ; Figure $2 \mathrm{~b}$ ), Bonferroni post hoc test indicates significant differences $(p<0.001)$ comparing WT-basal $v s$ KO-basal, KO-basal $v s$ WT-TOC, and KO-basal vs KO-TOC. In brain slices, a reduction of total ROS production was observed with the in vitro $40 \mu \mathrm{M} \alpha$-tocopherol treatment for $24 \mathrm{~h}$ (repeated measurement comparisons by ANOVA of tocopheroltreated groups $v s$ basal groups, $\mathrm{F}=1018, \mathrm{df}=3$, $p<0.0001$, \% of total variation 97.06; Figure 2d), Bonferroni post hoc test indicates significant differences $(P<0.001)$ comparing WT-basal vs KO-basal, WT-basal vs WT-TOC,
WT-basal vs KO-TOC, KO-basal vs WT-TOC, and KO-basal vs KO-TOC.

Antioxidant markers, such as reduced (Figure 3a) and oxidized GSH (Figure 3b), were measured after treatment trials. These two parameters were altered in vehicle Fmr1KO mice compared to vehicle WT-control and were normalized in brain samples after chronic $100 \mathrm{mg} / \mathrm{kg} \alpha$ tocopherol treatment. Concurrently, the activity of key enzymes involved in GSH homeostasis, such as GSHpx (Figure 3c) and GSHtf, (Figure 3d) were reduced in the vehicle Fmr1-KO mouse compared to WT-control level. Differences in the above-mentioned markers were also normalized in brain tissue from the Fmr1-KO mice after chronic $100 \mathrm{mg} / \mathrm{kg} \alpha$-tocopherol treatment. The effectiveness of the $\alpha$-tocopherol treatment to prevent oxidative stress was also analyzed measuring the carbonyl content of protein, a marker of protein oxidation. The total protein content was measured in brain tissue, and no significant difference was detected between genotypes or treatments (data not shown). However, the measurement of carbonyl content of protein in membrane fractions obtained from brain tissue of the vehicle Fmr1-KO group showed a significant increase compared to WT-vehicle group, and this increase was reversed under chronic $100 \mathrm{mg} / \mathrm{kg} \alpha$ tocopherol treatment (Figure 3e). Additionally, an increase in lipid peroxidation (TBARS) was observed in the vehicle Fmr1-KO mouse in comparison to the WT-control level, and this parameter was also normalized after chronic $100 \mathrm{mg} / \mathrm{kg} \alpha$-tocopherol treatment (Figure 3f ). Interestingly, the oxidative stress alterations indicated above remain altered after the chronic treatment with $50 \mathrm{mg} / \mathrm{kg} \alpha$ tocopherol.

To characterize the effectiveness of $\alpha$-tocopherol with respect to the enhanced testicular weight of the fragile $X$ mouse, we measured the weight and the oxidative stress parameters in testes of the Fmr1-KO, compared to both treated WT-control and vehicle Fmr1-KO groups. The Fmr1-KO mice group shows a normalization of the increased testicular weight (Supplementary Figure S2a) with $100 \mathrm{mg} / \mathrm{kg} \alpha$-tocopherol chronic treatment; however, $50 \mathrm{mg} / \mathrm{kg}$ of $\alpha$-tocopherol fails to normalize the testicular size. The reduced (Supplementary Figure S2b) and oxidized (Supplementary Figure S2c) GSH levels in the testicles were only normalized with a high dose of $100 \mathrm{mg} / \mathrm{kg} \alpha$-tocopherol in the Fmr1-KO group. The enzymatic activities related to GSH in the Fmr1-KO testes showed a comparable level to the WT-control group with $100 \mathrm{mg} / \mathrm{kg} \alpha$-tocopherol treatment (Supplementary Figure S2d). Carbonyl content was measured in the cytosol and membrane proteins in the dose-response treatment trial, the higher dosage of $\alpha$ tocopherol normalized the altered parameter in the Fmr1KO testes (Supplementary Figure S2e). The normalization of the TBARS level was observed in the Fmr1-KO group when a high dose of $100 \mathrm{mg} / \mathrm{kg}$ of $\alpha$-tocopherol was used (Supplementary Figure S2f). The lower dose of $50 \mathrm{mg} / \mathrm{kg}$ $\alpha$-tocopherol used in this trial failed to normalize all the biochemical oxidative parameters and the testicular weight (Figure 2). The complete data of the oxidative stress parameters measured in different mouse tissues after the $\alpha$-tocopherol trial can be found in Supplementary Table S4. Two-way ANOVA with Bonferroni post hoc test was performed to analyze statistical significant differences: 
a ENDOGEN FREE RADICAL SPECIES (Macrophage cells)

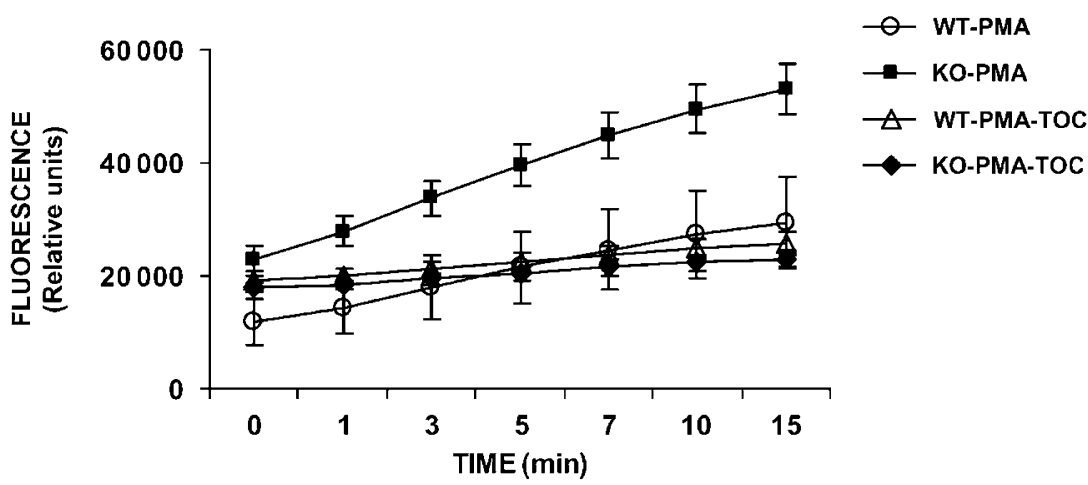

ANOVA

Bonferroni's Multiple Comparison Test WT-PMA vs KO-PMA

WT-PMA vS WT-PMA-TOC

WT-PMA vs KO-PMA-TOC

KO-PMA vs WT-PMA-TOC

KO-PMA vs KO-PMA-TOC

WT-PMA-TOC vS KO-PMA-TOC

$\begin{array}{ccc}t & p \text {-value } & 95 \% \text { Cl of diff } \\ 7.635 & p<0.001 & -82780 \text { to }-37490 \\ 1.615 & p>0.05 & -9928 \text { to } 35360 \\ 0.9270 & p>0.05 & -29950 \text { to } 15340 \\ 9.249 & p<0.001 & 50210 \text { to } 95500 \\ 6.708 & p<0.001 & 30190 \text { to } 75480 \\ 2.542 & p>0.05 & -42670 \text { to } 2627\end{array}$

b TOTAL ROS PRODUCTION (Brain slices)

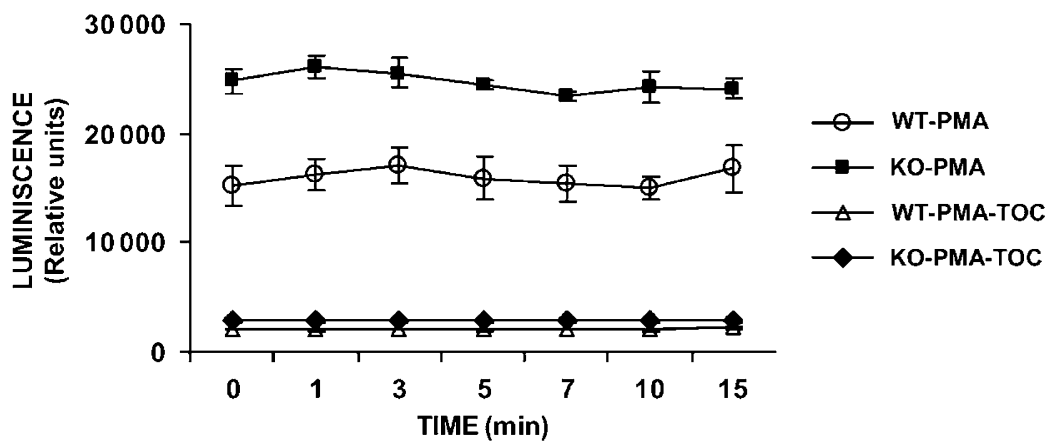

ANOVA

Bonferroni's Multiple Comparison Test
WT-PMA vs KO-PMA
WT-PMA vs WT-PMA-TOC
WT-PMA vs KO-PMA-TOC
KO-PMA vs WT-PMA-TOC
KO-PMA vs KO-PMA-TOC
WT-PMA-TOC vs KO-PMA-TOC

$\begin{array}{clc}t & p \text {-value } & 95 \% \text { Cl of diff } \\ 27.63 & p<0.001 & -9647 \text { to }-7828 \\ 49.57 & p<0.001 & 14770 \text { to } 16590 \\ 48.90 & p<0.001 & 14560 \text { to } 16370 \\ 77.19 & p<0.001 & 23500 \text { to } 25320 \\ 76.52 & p<0.001 & 23290 \text { to } 25110 \\ 0,6690 & p>0.05 & -1121 \text { to } 697.7\end{array}$

Figure 2 The Fmrl-knockout mice display an increase in ROS production in macrophage cells and brain slices, compared to wild-type (WT) mice. (a)

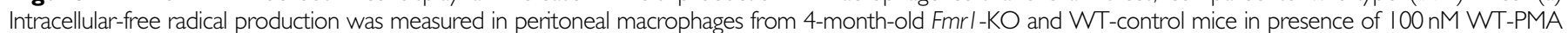

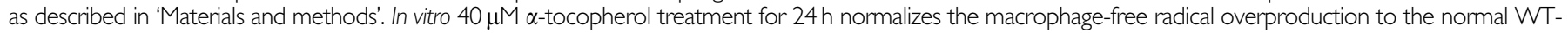

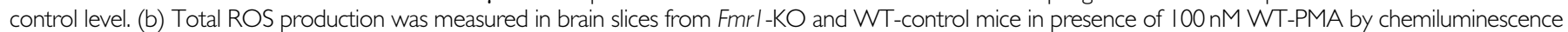

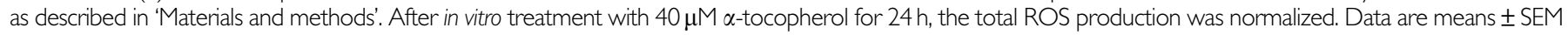
of at least 6-8 mice per group. Statistical significance was assessed by repeated measurements ANOVA, followed by Bonferroni post-test.

$p<0.05$ vehicle-KO vs vehicle-WT. $p<0.05$ vehicle Fmr1KO vs treated Fmr1-KO.

\section{Chronic $\alpha$-Tocopherol Treatment Restored Behavioral and Hormonal Abnormalities in a Time-Dependent Manner in Fmr1 Knockout}

The 30-day chronic treatment with $100 \mathrm{mg} / \mathrm{kg} \alpha$-tocopherol normalized several behavioral markers, such as the hyperactivity displayed by the Fmr1-KO mice measured as total distance traveled in the open field (Figure 4a) and also the altered anxiety response assessed in the elevated P-maze under nonstressed conditions (Figure 4b). The Fmrl-KO groups were compared to the WT-control group under vehicle treatment. Surprisingly, the anxiety response is also normalized in the Fmr1-KO group after 10 days of treatment (Figure 4b). The 30-day trial clearly normalized the testicular weight (Figure 4c). Additionally, $100 \mathrm{mg} / \mathrm{kg}$ $\alpha$-tocopherol treatment for 30 days also normalized the reduced corticosterone plasma level in the Fmr1-KO mice 

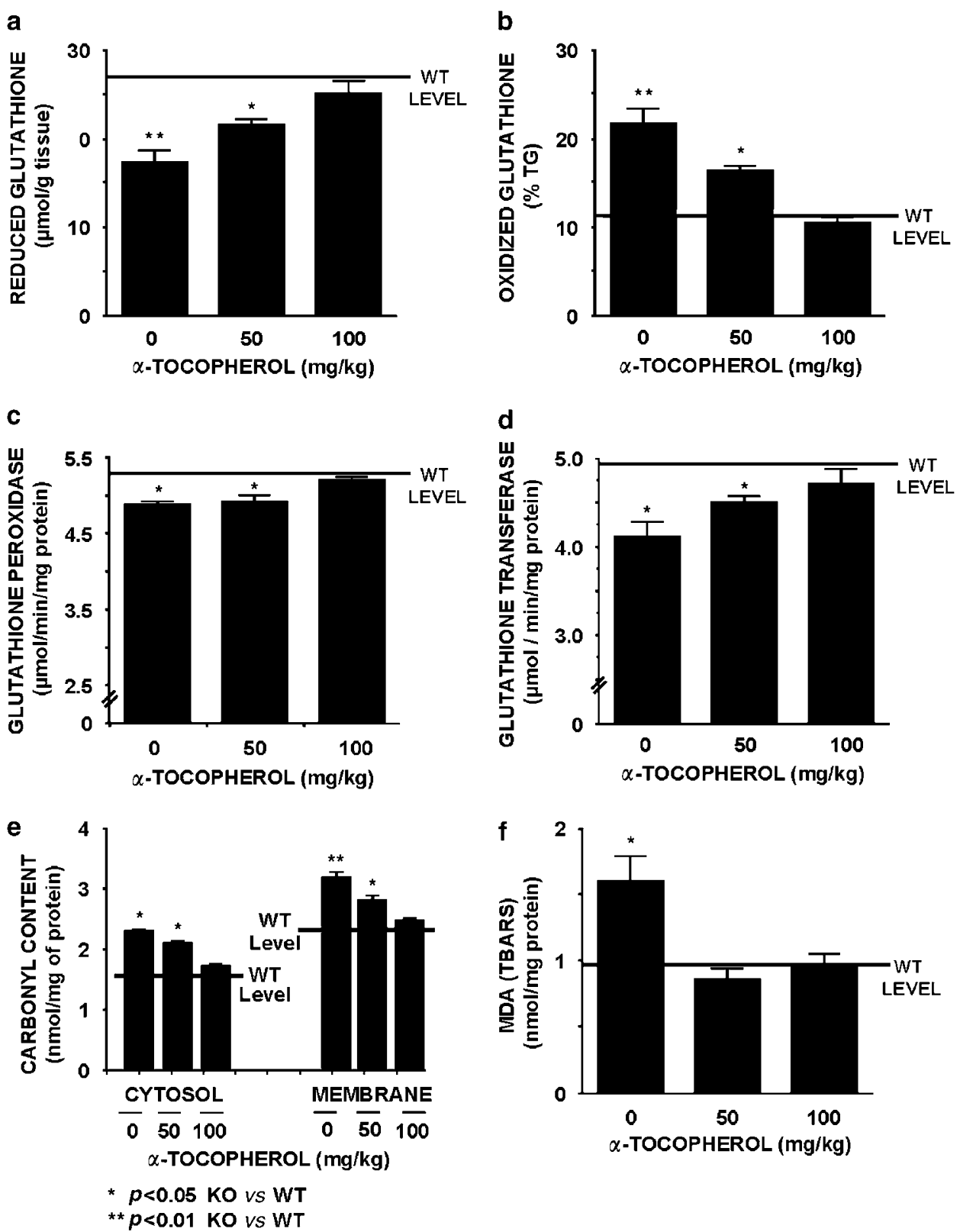

Figure 3 Dose-response curve of chronic $\alpha$-tocopherol treatment over oxidative stress in the brain from the Fmrl-knockout mice in comparison to the WT-control groups. Black horizontal line indicates the level of the selected parameter in wild-type (WT) littermates as a mean between vehicle-controls and WT treated with $\alpha$-tocopherol under the highest-dose regimen. Two markers of tissue antioxidant capacity were measured in brain, (a) levels of reduced glutathione and (b) levels of oxidized glutathione. Two markers of tissue glutathione metabolism were measured in brain (c) glutathione peroxidase level and (d) levels of glutathione transferase. (e) Levels of carbonyl content of protein as a marker of protein oxidation. (f) Levels of MDA in the brain measured as thiobarbituric acid reactive substances (TBARS), a lipid peroxidation marker. Data are means \pm SEM of at least $8-12$ mice per group. Statistical significance of quantification was assessed by repeated measurements ANOVA, followed by Bonferroni post-test. $* p<0.05$ and $*$ * $p<0.0$ I Fmrl -KO vs WT-control levels.

compared to the WT-control (Figure 4d). The reduced GSH level (Figure 4e) in the Fmr1-KO group is similar to WTcontrol level after the 30 days of $100 \mathrm{mg} / \mathrm{kg} \alpha$-tocopherol treatment. The normalization of the TBARS level occurs in the Fmr1-KO group after 30 days of $100 \mathrm{mg} / \mathrm{kg}$ of $\alpha$-tocopherol treatment (Figure $4 \mathrm{f}$ ).

To study the effectiveness of $\alpha$-tocopherol treatment in hippocampal/amygdala learning deficits, we analyzed learning fear conditioning by using of the Shuttle-box paradigm. The Fmr1-KO mouse in naïve and vehicletreated conditions showed less freezing response than the WT-control group in contextual and cued experiments during the testing session (Figure $5 \mathrm{a}$ and $\mathrm{b}$ ). Differences between genotypes are not observed when the mouse groups received a chronic $100 \mathrm{mg} / \mathrm{kg} \alpha$-tocopherol treatment, in the different sessions of the experiment (Figures $5 \mathrm{a}$ and $\mathrm{b}$ ).

Chronic Treatment with $100 \mathrm{mg} / \mathrm{kg} \alpha$-Tocopherol Inhibited Rac1-GTPase Activation and PKC- $\alpha$ Phosphorylation In Fmr1 Knockout

The Fmr1-KO mice showed an increase in Racl activation (Figure 6a) in brain obtained from the vehicle-group and 
a
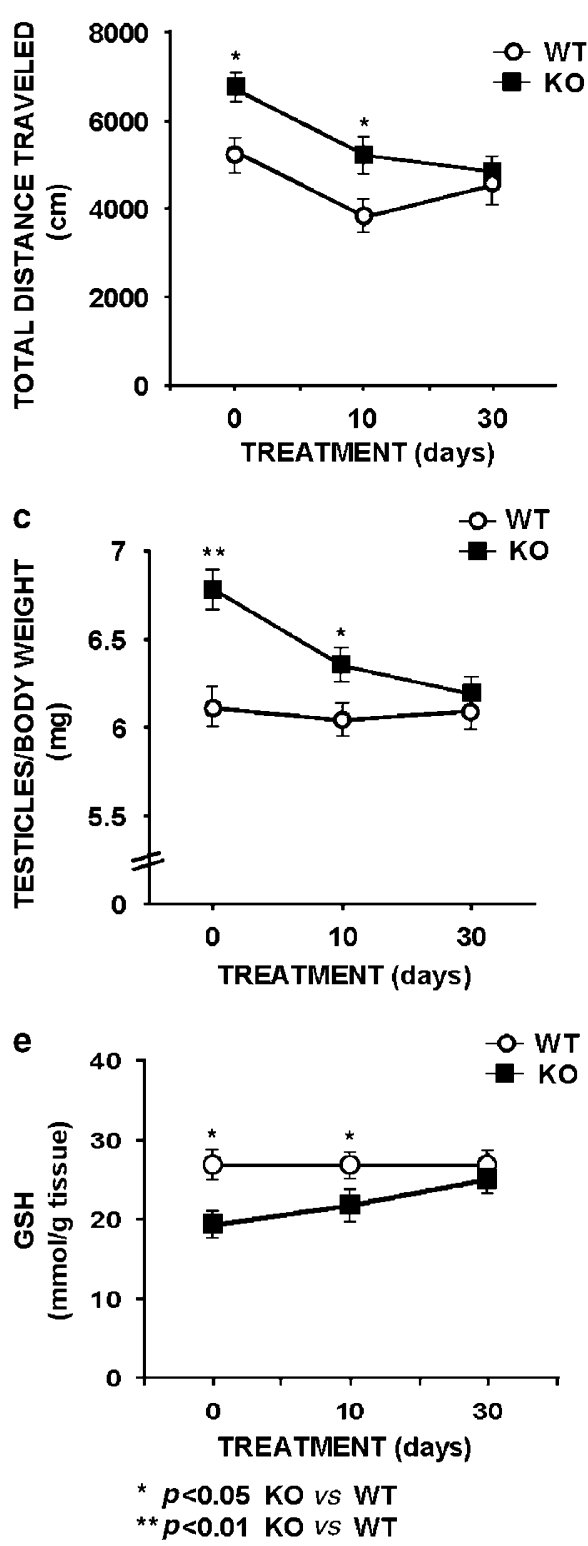

b
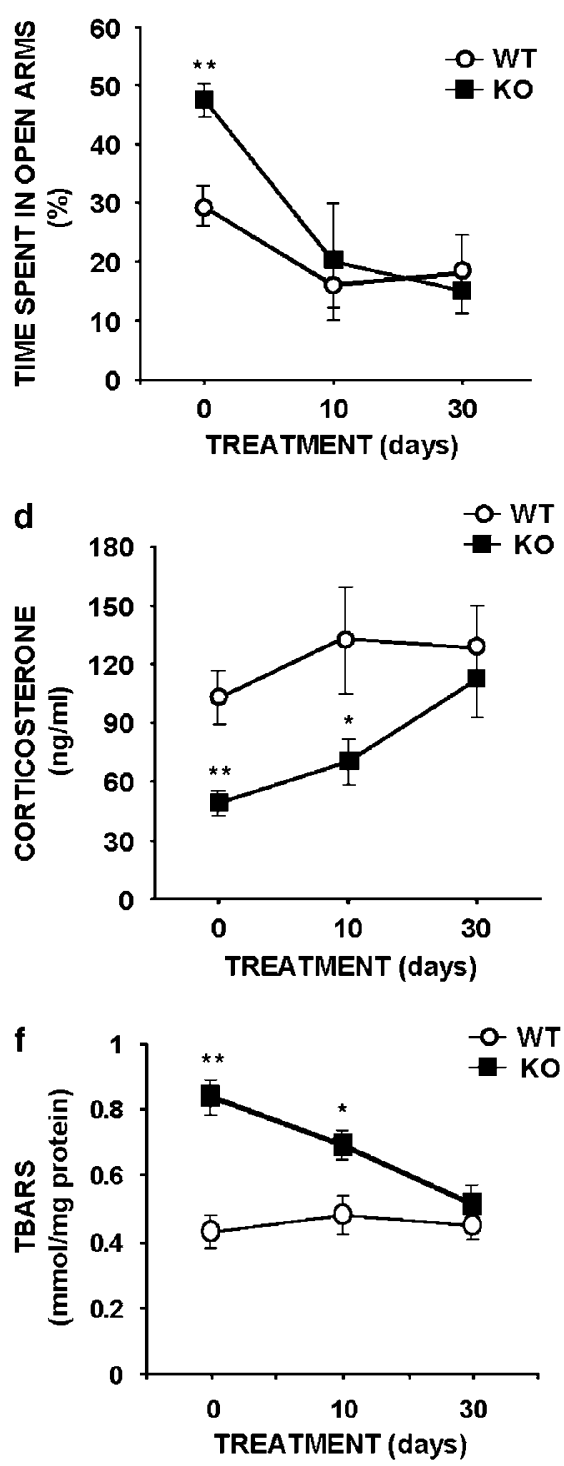

Figure 4 Time-course effects of chronic $\alpha$-tocopherol treatment over behavior, testicular weight, corticosterone plasma levels, and testicular oxidative stress (GSH and TBARS markers) in the Fmrl-knockout mice in comparison to the WT-control groups. Treatment for 0, I0, and 30 days with I00 mg/kg $\alpha$ tocopherol showed that only chronic treatment for 30 days could normalize the measured parameters. (a) Hyperactivity observed in the open field at 0 and 10 days of treatment was normalized after 30 days of uninterrupted treatment. (b) Exploratory activity in the elevated P-maze showed an increase of time spent in the exposed arms as a parameter of anxiolysis and was normalized after 10 days of treatment reaching normal levels after 30 days. (c) The increased weight of testicles in the Fmrl-KO mouse group in comparison to the WT-control group was only normalized after 30 days of treatment. (d) Basal corticosterone secretion measured in plasma obtained in the morning was decreased in the Fmrl-KO mouse group in comparison to the WT-control group. This parameter is only normalized after 30 days of treatment. (e) Levels of testicular reduced glutathione, as marker of antioxidant status. ( $f$ ) Levels of testicular thiobarbituric acid reactive substances (TBARS) as a lipid peroxidation marker. Data are means \pm SEM of at least 8-12 mice per group. Statistical significance of quantification was assessed by repeated measurements ANOVA, followed by Bonferroni post-test. * $p<0.05$, ** $p<0.01$ Fmrl-KO vs WTcontrol level.

similar results were found in testicles. The chronic $100 \mathrm{mg} /$ $\mathrm{kg} \alpha$-tocopherol treatment reduced the activation of Rac1 to a normal level in the brain and testicles of the Fmr1-KOtreated group compared to Fmr1-KO vehicle group. However, total level of Racl protein is similar between genotypes when vehicle-group is compared to $\alpha$-tocopheroltreated groups (Figure 6a). The densitometry analysis of three different experiments run in parallel showed similar results, and the mean \pm SEM of the signal is represented for brain and testicles in the different groups.

We also studied PKC- $\alpha$ activation due to excessive free radical production observed in the Fmr1-KO mice. In naïve conditions, an increase in brain PKC- $\alpha$ phosphorylation is detected in the Fmr1-KO in comparison to the WT-control mice in nave- and vehicle-treated conditions. The chronic $100 \mathrm{mg} / \mathrm{kg} \alpha$-tocopherol treatment reduces brain PKC- $\alpha$ 
a

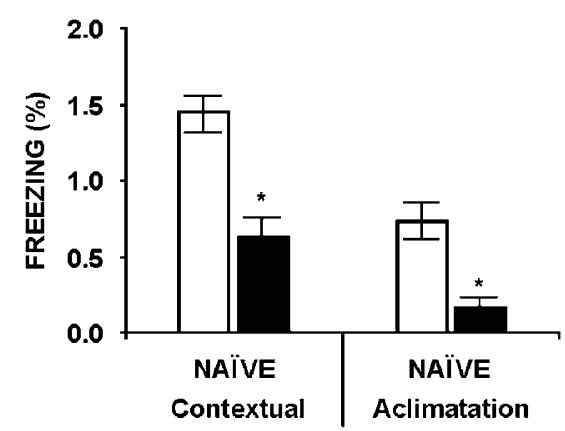

b

TESTING
TESTING

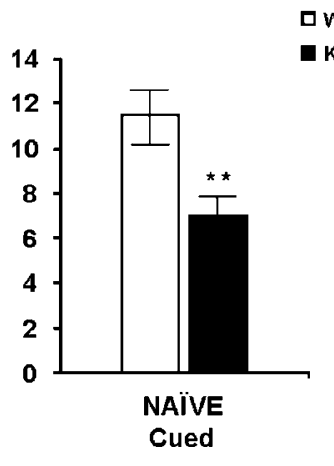

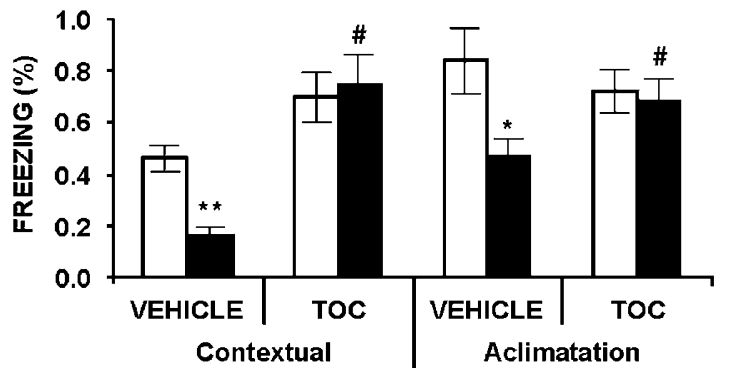

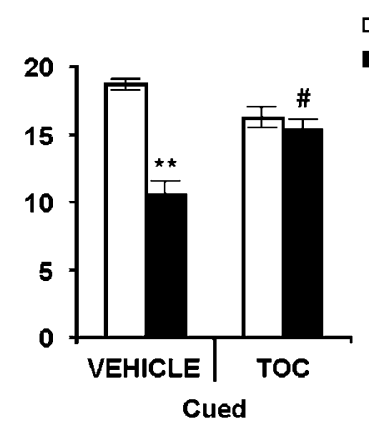

$\star p<0.05$ KO vs WT

$\star \star p<0.01 \mathrm{KO}$ vs WT

\# $p<0.05$ Treated-KO vs Vehicle-KO

Figure 5 The absence of FMRP protein impairs cued and contextual fear conditioning and chronic $100 \mathrm{mg} / \mathrm{kg} \alpha$-tocopherol (TOC) treatment improves hippocampal learning deficits observed in the Fmrl-KO mouse model. We measured contextual and cued fear conditioning to study the hippocampal function through Shuttle-box paradigms. (a) At $24 \mathrm{~h}$ after a training session, the mouse is tested for 5 min in the training chamber with no tone or shock presentation, and observed for freezing behavior (contextual fear conditioning). An hour later, the mouse was placed in a different chamber and observed for freezing for 2 min acclimatization. Then, the conditional stimuli (CS) is presented for 3 min, during which the freezing behavior is also measured (cued fear conditioning). The Fmrl-KO mouse groups displayed significantly decreased levels of freezing for contextual and cued fear conditioning, in comparison to the WT-control group under naïve conditions. (b) Chronic $100 \mathrm{mg} / \mathrm{kg} \alpha$-tocopherol treatment normalized the measured markers of hippocampal/amygdala memory deficits observed in the Fmrl-KO mouse. Data are means \pm SEM of at least 8-12 mice per group. *p $<0.05$, ** $p<0.01$ Fmrl-KO vs WT-control level. ${ }_{p} p<0.05$ treated-KO vs treated-WT.

phosphorylation in Fmr1-KO mice to levels observed in control groups, as can be seen in a representative western blot and in densitometry analysis of three different experiments run in parallel (Figure 6b).

\section{NAC Treatment was Unable to Normalize all Phenotypic Alterations in Fmr1 Knockout}

Chronic treatment with $200 \mathrm{mg} / \mathrm{kg}$ NAC for 30 days failed to normalize several abnormal markers measured to the Fmr1KO mouse (Supplementary Table S5. Two-way ANOVA with Bonferroni post hoc test was performed to analyze statistical significant differences). Surprisingly, the percentage of time spent in the exposed arms of the P-maze was reduced in the treated Fmr1-KO mice and reached WT-control levels after chronic NAC treatment indicating a positive effect on anxiety response, a similar result is observed in the Fmr1$\mathrm{KO}$ TOC + NAC-treated group (Figure 7a). Total distance traveled in the open-field maze was elevated in the Fmr1-KO vehicle- and NAC-treated groups in comparison to the WTcontrols, but an attenuation of the difference is observed in the Fmr1-KO NAC-treated group (Figure 7b). The Fmr1-KO TOC + NAC-treated group shows normal locomotor activity. These results indicate that NAC treatment was not adequate to reverse the behavioral deficits of the fragile $\mathrm{X}$ mouse. Unexpectedly, the absence of the habituation response observed in the Fmr1-KO mice in naïve or vehicle conditions was normalized after chronic treatment with $200 \mathrm{mg} / \mathrm{kg}$ NAC. The 30-day NAC-treatment trial clearly fails to normalize the testicular weight in the Fmr1-KO mouse (Figure 7c). Also, the TBARS level remains elevated in brain tissue from Fmr1-KO mice (Figure 7d).

Testosterone levels are unchanged in vehicle and treated groups (Figure 7e). Corticosterone levels are reduced in the Fmr1-KO mice in vehicle condition and this parameter is normalized by TOC $+\mathrm{NAC}$ treatment and it remains diminished in the Fmr1-KO mice after chronic $200 \mathrm{mg} / \mathrm{kg}$ per day NAC treatment (Figure 7f).

Chronic treatment with a combination of $100 \mathrm{mg} / \mathrm{kg} \alpha$ tocopherol and $200 \mathrm{mg} / \mathrm{kg}$ NAC for 30 days normalized the abnormal markers measured in the Fmr1-KO mouse (Supplementary Table S6. Two-way ANOVA with Bonferroni post hoc test was performed to analyze statistical significant differences).

\section{DISCUSSION}

The description of altered levels of excitatory amino acids, and the abnormal expression of genes involved in redox 

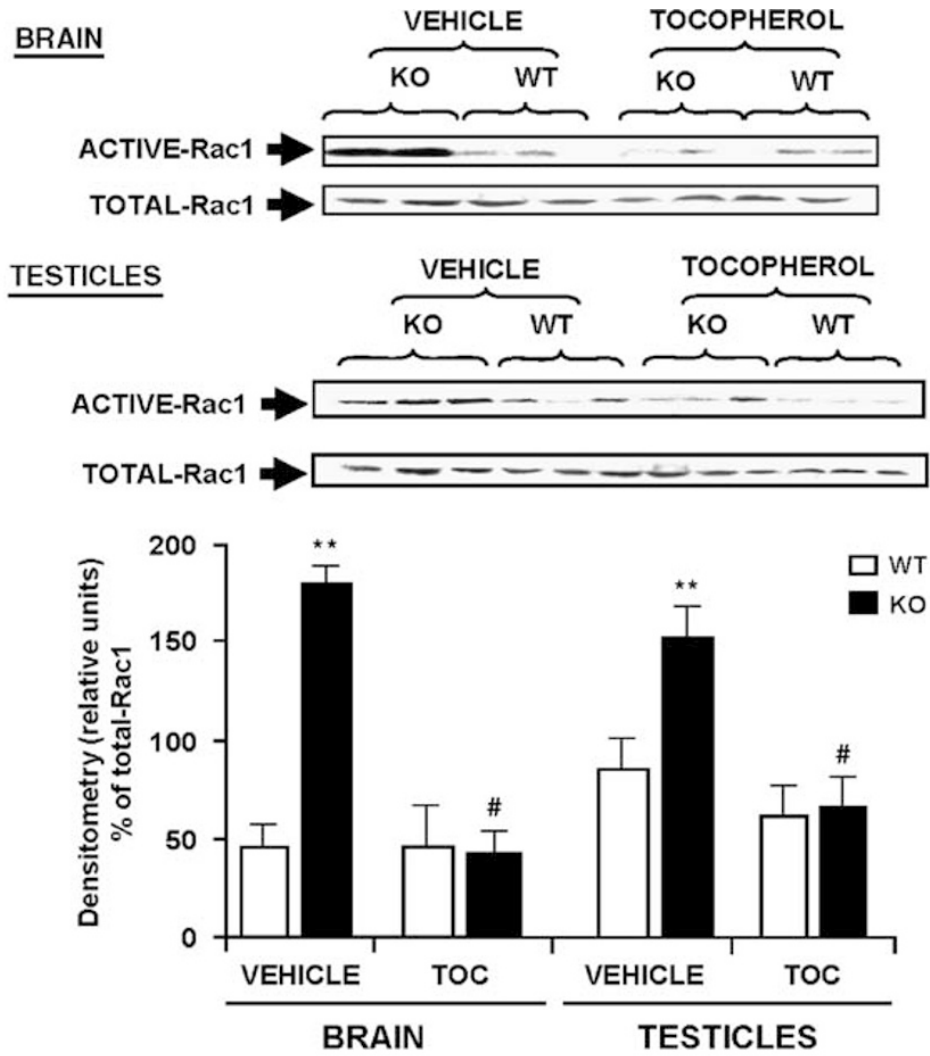

b BRAIN
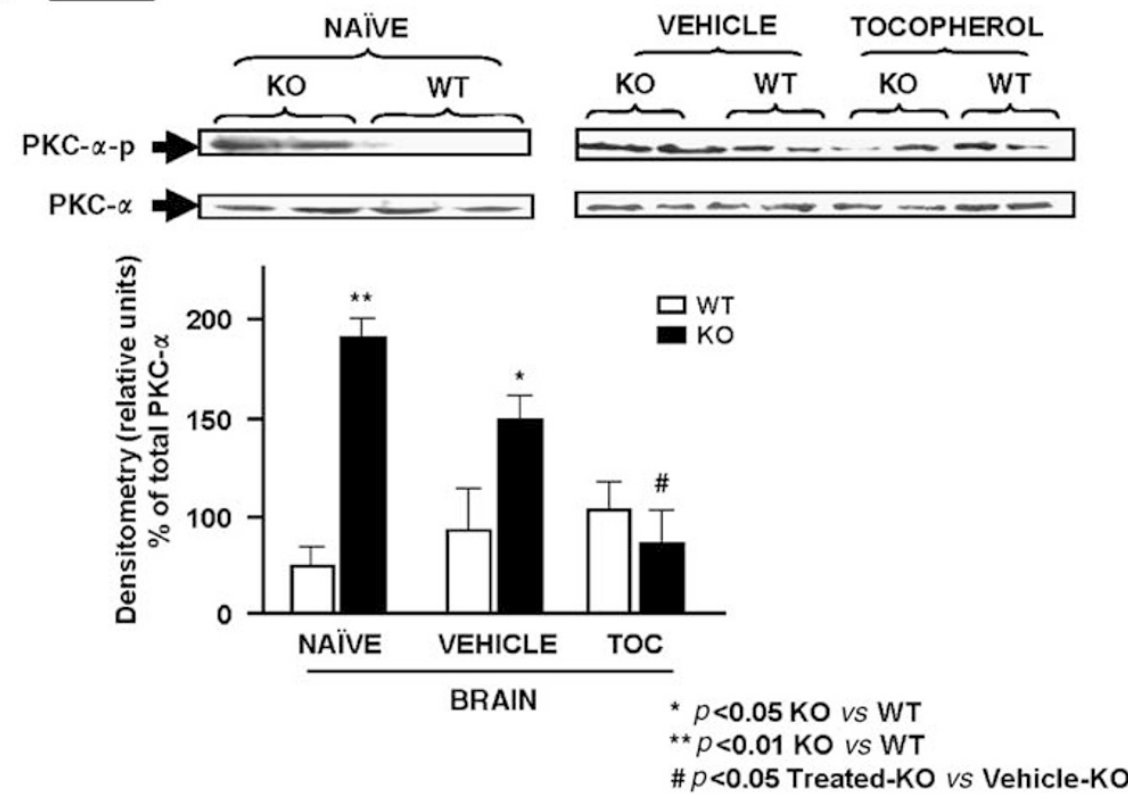

Figure $6 \mathrm{Racl}$ GTP-binding activity and PKC- $\alpha$ phosphorylation were decreased after chronic treatment with $100 \mathrm{mg} / \mathrm{kg}$ of $\alpha$-tocopherol (TOC) in the Fmrl-knockout (KO) mice. (a) In naïve conditions, the Racl GTP-binding activity was increased in brain and testes from Fmrl-KO groups in comparison to WT-controls and chronic tocopherol treatment reversed the hyperactivation in 4-month-old Fmrl-KO compared to wild-type (WT) mouse groups, Each blot is representative of a set of three experiments that yielded similar results. The lower panel shows the Racl densitometry analysis of three experiments. (b) PKC- $\alpha$ phosphorylation was activated in the brain from the Fmrl-KO mice compared to WT mice in naive conditions, whereas the total PKC- $\alpha$ was unchanged between genotypes. The treatment of the mouse groups with $100 \mathrm{mg} / \mathrm{kg}$ of $\alpha$-tocopherol (TOC) normalizes the phosphorylated level of PKC- $\alpha$. Each blot is representative of a set of three experiments that yielded similar results. The densitometry analysis of all set of experiments can be observed in the bottom graph of the panel. Data are means \pm SEM of 6-9 mice per group. ${ }^{*} P<0.05,{ }^{*} * P<0.0$ I Fmr I-KO vs WT-control level. ${ }^{\#} P<0.05$ treated-KO vs treated-WT. 

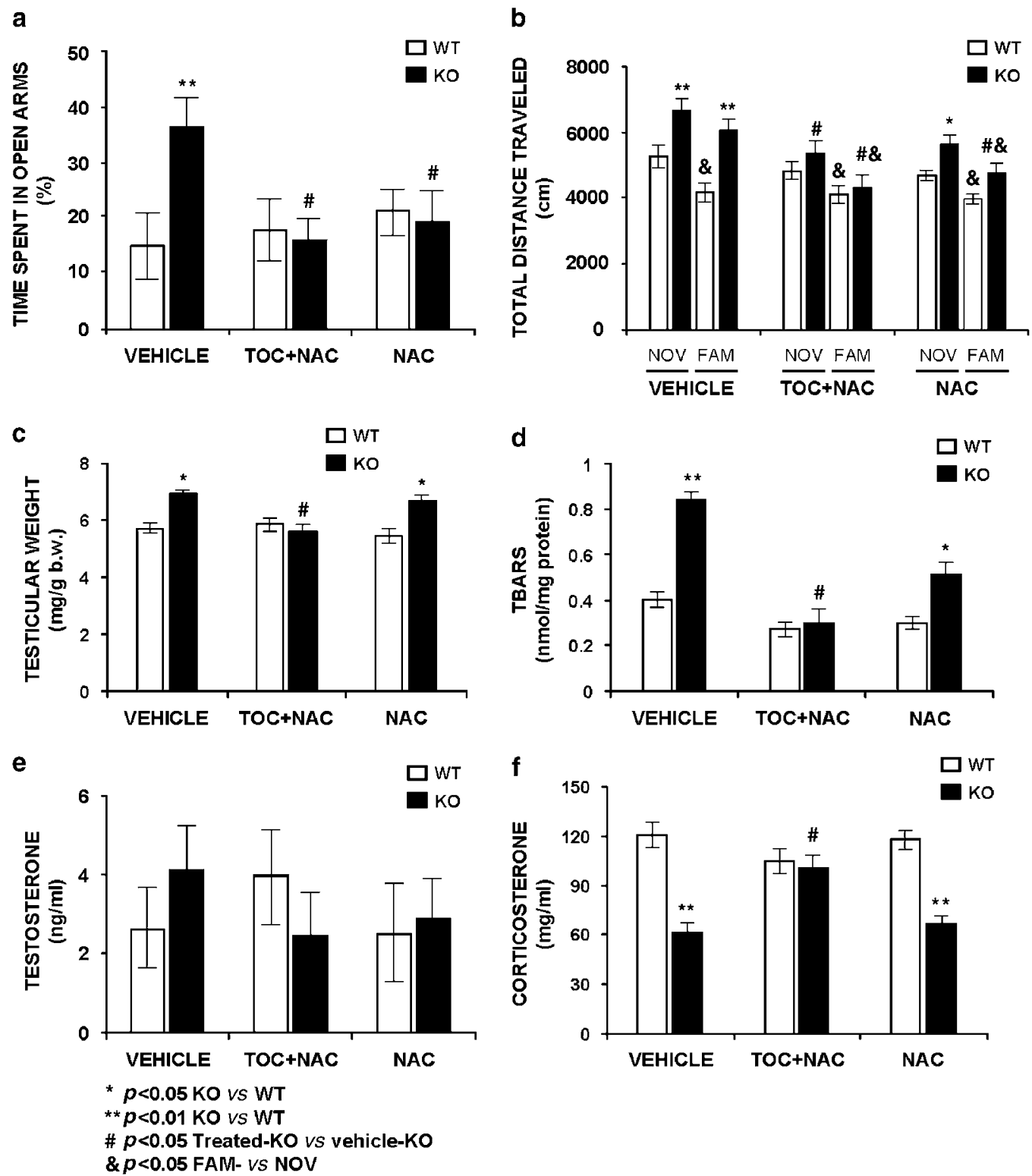

Figure 7 Chronic trials either with vehicle, a combination of $100 \mathrm{mg} / \mathrm{kg} \alpha$-tocopherol (TOC) $+200 \mathrm{mg} / \mathrm{kg} \mathrm{N}$-acetyl-L-cysteine (NAC) or $200 \mathrm{mg} / \mathrm{kg} \mathrm{NAC}$ showed positive effects of $\alpha$-tocopherol treatment in comparison to NAC. (a) Exploratory activity in the elevated P-maze showed an increase of time in the exposed arms as a parameter of anxiolysis in the Fmrl-KO vehicle group in comparison to the WT-control group. This alteration was normalized after chronic treatment with either the combined formula or the single formula, showing a normal anxiety response either with NAC or $\alpha$-tocopherol. (b) The Fmrl-KO group showed an enhanced hyperactivity in both novelty (NOV) and familiarity (FAM) environments and also an absence of habituation of the vehicle Fmr $\mathrm{KO}$ group in comparison to the vehicle WT-control group. The distance traveled and habituation was normalized after chronic treatment with the combined formula in the Fmrl-KO group in comparison to the treated-WT-control and to vehicle-WT groups. The chronic treatment with NAC reduced the distance traveled in the Fmrl-KO group but was not completely normalized; however, the habituation response was observed after the NAC treatment, indicating a specific positive effect of NAC in this learning parameter. (c) The combined formula of $100 \mathrm{mg} / \mathrm{kg} \alpha$-tocopherol $+200 \mathrm{mg} / \mathrm{kg}$ NAC normalized the increased testicular weight observed in vehicle-Fmrl-KO and NAC-Fmrl-KO groups. (d) The combined formula also normalized the increased levels of TBARS observed in the vehicle-Fmrl-KO. NAC (200 mg/ $/ \mathrm{kg})$ significantly diminished the TBARS level in the testicles of the Fmrl-KO group in comparison to the vehicle-Fmrl-KO group, but could not normalize the level to WT-control groups. (e) Testosterone plasma levels were measured in the three conditions in both Fmrl-KO and WT-control groups. No significant differences were observed between genotypes in the compared groups. (f) In the Fmrl-KO, the corticosterone levels were diminished in both vehicle- and NAC-treated groups, in comparison to the WT-control groups. The chronic treatment with a combined formula normalized the corticosterone plasma levels in the Fmrl-KO in comparison to the WT-control groups. Data are means \pm SEM of at least $8-$ 12 mice per group. ${ }^{*} p<0.05,{ }^{*} * p<0.01$ Fmrl-KO vs WT-control level. ${ }^{*} p<0.05$ treated KO vs treated WT. ${ }^{*} p<0.05$ FAM vs NOV.

homeostasis in Fmr1-KO mice (Brown et al, 2001; Miyashiro et al, 2003; Gruss and Braun, 2004), together with our previous results demonstrating that NADPHoxidase activation as a major source of extracellular oxygenfree radical production in the brain of the fragile $\mathrm{X}$ mouse model (El Bekay et al, 2007), prompted us to study the existence of oxidative stress. As phenotypic alterations of fragile X patients and Fmr1-KO mice are based on multiple molecular alterations, the existence of an abnormal substrate in redox homeostasis might be a common 
pathway to excitotoxicity and may offer new targets for therapeutic investigation.

The present findings indicate that a chronic treatment of $\alpha$-tocopherol correlated significantly with a significant improvement in the Fmr1-KO mouse phenotype. The major lines of evidence provided in this study are: (1) Fmr1-KO mouse showed stress-dependent alterations in behavioral parameters and adrenal hormonal secretion. (2) Fmr1-KO mouse tissue displayed a statistically moderate tissuedependent increase in oxidative stress markers found in testicles, pancreas, and salivary glands in addition to the already described brain oxidative stress. The altered oxidative-stress parameters were lipid peroxidation, protein oxidation, and an abnormal GSH metabolism in the first 4 months of development. (3) Following the in vitro treatment of $\alpha$-tocopherol, free radical production was at the normal range in Fmr1-KO macrophage cells and brain slices, in comparison to the WT-controls. (4) A possible proposed mechanism, for oxidative stress normalization following $\alpha$ tocopherol treatment, is the inactivation of Rac1-GTPase, a protein controlling NADPH-oxidase activity and free radical production. (5) Intraperitoneal chronic treatment of $100 \mathrm{mg} / \mathrm{kg} \alpha$-tocopherol every second day to 3 -month-old mice was able to normalize exploratory behaviors, habituation abnormalities, anxiety responses, and contextual fear conditioning. These paradigms were altered in the Fmr1-KO groups in comparison to the WT-controls before treatment. (6) Increasing the antioxidant capacity with $200 \mathrm{mg} / \mathrm{kg}$ NAC chronic treatment did not normalize the corticoadrenal hormonal secretion, the lipid peroxidation in brain and testicles, the increased testicular weight, or the altered exploratory behaviors observed in the open-field paradigm, but a positive effect was observed in the anxiety response on the P-maze paradigm. (7) $\alpha$-tocopherol (50 mg/kg) or 10 day $100 \mathrm{mg} / \mathrm{kg} \alpha$-tocopherol trials were not able to normalize all the parameters measured throughout the study.

Therefore, all these findings together indicate that chronic treatment with a therapeutic dose of $100 \mathrm{mg} / \mathrm{kg} \alpha$-tocopherol, a major lipophilic antioxidant compound that controls the membrane source of free radicals, protected the Fmr1$\mathrm{KO}$ mouse from the oxidative stress pathology in brain and testes, the most affected organs described in the fragile $\mathrm{X}$ syndrome, reversing the principal behavioral and learning deficits.

All cells in the body are exposed chronically to oxidants from both endogenous and exogenous sources; however, an antioxidant system is also present to prevent cellular damage. Nutrients, both water-soluble and lipid-soluble antioxidants comprise an important aspect of the antioxidant defense system. Reactive oxygen and nitrogen species, if unrestricted, can contribute to chronic disease by oxidatively modifying lipids, proteins, and nucleic acids (Liu et al, 1996). Of all the organs, the brain is thought to be the most vulnerable to oxidative damage due to its high oxygen consumption, presence of high levels of polyunsaturated fatty acids and the nongeneral proliferative nature of neurons, which may lead to various neurodegenerative diseases (Floyd and Carney, 1992).

Different trials were performed during this study, a doseresponse and a time-course trial of $\alpha$-tocopherol. As a fatsoluble vitamin, $\alpha$-tocopherol has the potential for toxicity. However, it does appear to be the least toxic of the fat- soluble vitamins. No instances of toxicity have been reported at doses of $1600 \mathrm{mg}$ per day tocopherol (Das, 1994). There are previous works on daily systemic treatment with this antioxidant at a dose of $2350 \mathrm{mg} / \mathrm{kg}$ in monkeys to prevent toxicity. A recent publication demonstrated that a high dosage of tocopherol $(100,200$, and $400 \mathrm{mg} / \mathrm{kg})$ presented protective effects on ethanol-induced brain damage in mice (Guo et al, 2007).

The search for intervention strategies for the fragile $\mathrm{X}$ syndrome has been boosted by the development of KO mice (Bakker et al, 1994). One important outcome of this model is the identification of physiological pathways contributing to the pathogenesis. We have already described in a previous work the implication of oxidative stress as a primary factor involved in Fmrl-KO brain pathophysiology (el Bekay et al, 2007). The experimental procedure is now supported by the correction of deleterious effects of oxidative stress with $\alpha$-tocopherol chronic treatment. Although we cannot rule out the possibility that parallel changes in other affected pathways also contribute to behavior deficits and cognitive impairment, our results support the hypothesis that increased free radical levels and Rac1-GTPase activation contribute to oxidative stress, and may be involved in $\alpha$-tocopherol positive effects. Our data also support the idea that the increase of lipid soluble antioxidant capacity could be considered as a potential neuroprotective strategy for the fragile $\mathrm{X}$ syndrome.

Time- and tissue-dependent oxidative stress was detected in the Fmr1-KO mouse, and appears in the first 4 months of postnatal life. It is associated with well-known phenotypic alterations like increased free radical production, macroorchidism, context-dependent abnormal exploratory and anxiety behaviors, abnormal contextual fear conditioning, and disturbed hormonal stress responses. The oxidative stress might lead to the early onset of the phenotype in young Fmr1-KO, it was already described and agedependent altered excitatory neurotransmitter levels in brains from the young Fmr1-KO mouse (Gruss and Braun, 2004).

This new piece in the fragile $X$ puzzle suggests that the pathophysiological alterations observed in brain and testicles, the main affected organs in the fragile $\mathrm{X}$ syndrome, may be due to an exacerbated increase of the oxidative status and possibly maintained by the abnormal secretion of adrenal hormones released during daily stressful events, and may be related to molecular alterations such as Rac1GTPase activation leading to free radical overproduction. These hallmarks occur in the absence of FMRP function. This hypothetical model of the fragile $\mathrm{X}$ syndrome may explain both the vague phenotype, with multiple subtle dysfunctions, and the existence of clear alterations in early childhood that remain in adulthood. Following this rationale, we have confirmed that Fmr1-KO mice display stress-related context-dependent alterations in exploratory/ anxiety behaviors associated with altered levels of plasma glucocorticoids. Human studies support these findings as there are reports showing the existence of a dysregulation of the HPA axis in fragile X patients, which exhibit high levels of cortisol (Hessl et al, 2002). Adrenal steroids typically have adaptive effects in the short run, but cause pathology when there is either repeated stress or dysregulation of the HPA axis (Virgin et al, 1991; Weber, 1999). High 
glucocorticoid levels impair declarative, spatial, and contextual memory in a reversible manner (Magarinos and McEwen, 1995). We have observed a normalization of corticosterone levels by $100 \mathrm{mg} / \mathrm{kg} \alpha$-tocopherol treatment. In agreement with our results, it has been published that plasma corticosterone was significantly reduced to the control values in stressed rats by $150 \mathrm{mg} / \mathrm{kg} \alpha$-tocopherol treatment (Ainsah et al, 1999).

The molecular basis of oxidative stress contribution to the Fmr1-KO mouse phenotype was previously analyzed, showing that NADPH-oxidase activation can be a major source of extracellular oxygen-free radical production in the brain (El Bekay et al, 2007). Neurons are highly vulnerable to the oxidant threat because of its high rate of aerobic metabolism and the elevated concentration of oxidizable molecules. An excess of highly oxidizable molecules (catecholamines) or the hyperactivation of glucocorticoid receptors in the brain causes neuronal excitotoxicity through a redox-dependent inhibition of the activity of glutamate reuptake transporters that may ultimately lead to neuronal damage in the hippocampus, cortex, and cerebellar vermis (Weber, 1999). In addition to free radical toxicity, the origin of oxidative stress in Fmr1-KO mice may also be related to the inadequate translation of proteins involved in metabolism, redox status, and vesicular organ dynamics (Wautier et al, 2001). This is supported by microarray identification of altered mRNA translational profiles in the absence of FMRP, including proteins such as GSHtf and superoxide dismutase (Brown et al, 2001). These proteins participate in maintaining a balanced antioxidant status, and we had shown in this study that the activity of GSHtf is abnormal in Fmr1-KO mice. Additionally, the Fmr1-KO model showed an altered mRNA expression of glucocorticoid receptors and desaturase enzyme, (Miyashiro et al, 2003). These genes played a key role in the metabolism and oxidative status of the cell.

The identification of $\alpha$-tocopherol nonantioxidant actions led us to examine whether Racl inactivation may be involved in the restoration of the phenotypic Fmr1-KO mouse hallmarks. Rac1-GTPase was significantly activated in the brain and testes of the Fmrl-KO mouse and $\alpha$ tocopherol treatment reversed the activation to normal levels. Previous published works have provided evidence of an important function of Racl-GTPase in learning processes, observed in contextual fear conditioning tasks (Martinez et al, 2007). Our results indicate that the $\alpha$ tocopherol treatment reduced Racl activation and also normalizes the freezing response measured in the fear conditioning paradigm. All these results together may support the hypothesis of the possible relationship between Rac-1 inhibition and the positive learning effects of $\alpha$ tocopherol treatment, but other unknown pathways may also be involved in these positive effects.

Additionally, Rac1-GTPase (a protein interacting with FMR1P trough the CIFYP protein) is involved in controlling the formation of fine dendritic branches (Lee et al, 2003), and this protein is known to regulate vesicle neurosecretion (Doussau et al, 2000; Li et al, 2003), and free radical production (Sundaresan et al, 1996). Rac1-GTPase has two distinct roles at different stages of neuronal development. The activation of Racl initiates spine formation at an early stage and regulates the function and morphology of preexisting spines at a later stage. The expression of constitutively active Racl induces the formation of unusually large synapses with large amounts of AMPAR clusters. Activation of Racl enhances excitatory synaptic transmission by recruiting AMPARs to synapses during spine formation (Wiens et al, 2005). It is well known that abnormal dendritic spines are one of the fragile $\mathrm{X}$ characteristics (Grossman et al, 2006), which may be related to altered Racl activation, as we have demonstrated in our results, the RAC1 protein is hyperactivated in the brain and testicles of the Fmr1-KO mouse.

Also, previous reports have indicated that $\mathrm{PKC}-\alpha$ activity is regulated by redox status (Ward et al, 1998). Thus, a reduction in the GSH content in the brain induces an overactivation of the PKC- $\alpha$ signal, and its dephosphorylation was demonstrated under $\alpha$-tocopherol treatment (Zingg and Azzi, 2004). In our experimental conditions, we observed an increase of the phosphorylated form of the PKC- $\alpha$-activated protein in the brain of Fmr1-KO vs WTcontrols, together with a reduction in GSH levels. This indicates that PKC-dependent mechanisms are enhanced in these animals, modifying cellular physiology and helping to establish the altered phenotype of the Fmr1-KO mice. Treatment with $\alpha$-tocopherol markedly decreases the phosphorylation of PKC- $\alpha$ together with an increase in GSH levels. The target pathways of PKC- $\alpha$ activation involved in the described phenotypic alterations are unknown, but are probably not the only mechanisms involved in the restoration of the phenotype induced by $\alpha$-tocopherol. Additional studies must be done to better understand the altered molecular pathways involved in the fragile $\mathrm{X}$ phenotype.

In fact, alternative treatment with NAC, a GSH precursor, partially restores the phenotype described in the FMR1-KO mice, indicating that at least anxiety response may be reversed by the increase of the GSH sources. Recently, GSSGrd has been proposed as a specific protein involved in anxiety response in mouse models (Hovatta et al, 2005). We described altered GSSGrd activity in the brain from the Fmr1-KO mice, linking this finding to altered anxiety responses in the fragile $\mathrm{X}$ mouse. The treatment trials with either $\alpha$-tocopherol or NAC were able to reverse the altered GSH balance and the abnormal anxiety response. Brain oxidative stress is associated with long-term alterations in coping style, emotion and behavior, neuroendocrine responses, social 'fitness', as well as cognitive function, brain morphology, neurochemistry, and the expression of genes that have been related to anxiety/depression, learning, behavior, and mood disorders (Weber, 1999; McEwen, 2007).

In conclusion, the present study suggests that $\alpha$ tocopherol may reverse specific alterations associated with the lack of FMRP, the cause of fragile $\mathrm{X}$ syndrome. They included decreased GSH levels and GSH enzyme activities, lipid peroxidation, protein oxidation, and changes in regulatory proteins at the molecular level. At the organism level, changes are reflected in the reversal of certain pathophysiological hallmarks such as behavior, learning, hormonal secretion, and macroorchidism. The present study demonstrates for the first time that a selective antiperoxidative antioxidant, with neuroprotective properties, acts as a potential new experimental therapeutic 
intervention. Further research must be completed to understand the contribution of all these mechanisms to the human form of the disease and to establish the effectiveness of antioxidants to ameliorate health status for the fragile $\mathrm{X}$ syndrome, the most common inherited mental disability with reduced therapeutic alternatives.

\section{ACKNOWLEDGEMENTS}

We thank Prof B Oostra (Clinical Genetics Department, Erasmus Medical Center, Rotterdam) for the Fmr1 (FBV129) knockout mice and to DWE Ramsden for the paper revision.

\section{DISCLOSURE/CONFLICTS OF INTEREST}

This work was supported in part by grants from the Marie Curie European Program (grant MCFI-2000-01137), Conquer Fragile X Foundation (Florida, USA), Spanish Network for research (G03/098) and (G03/184), FEDER (EU), Spanish Ministry of Science and Technology (SAF2003-00200) and the Andalusian Health Service and Educational Service (SAS128/2003 and CTS-546). R El Bekay is a recipient of a post doctoral grant (FIS-2007) from the Spanish Ministry of Health. Y Romero is a recipient of a PhD student grant from the Andalusian Educational Service. L Sanchez is a recipient of a grant from the Spanish Ministry of Health. The authors declare that, except for the income received from their primary employer, no financial support or compensation has been received from any individual or corporate entity over the past 3 years for research or professional service and there are no personal financial holdings that could be perceived as constituting a potential conflict of interest.

\section{REFERENCES}

Ainsah O, Nabishah BM, Osman CB, Khalid BA (1999). Naloxone and vitamin $\mathrm{E}$ block stress-induced reduction of locomotor activity and elevation of plasma corticosterone. Exp Clin Endocrinol Diabetes 107: 462-467.

Bakker CE, Verheij C, Willemsen R, Van Der Helm R, Oerlemans F, Vermey M et al (1994). Fmr1 knockout mice: a model to study fragile X mental retardation. Cell 78: 23-33.

Bardoni B, Davidovic L, Bensaid M, Khandjian EW (2006). The fragile X syndrome: exploring its molecular basis and seeking a treatment. Expert Rev Mol Med 8: 1-16.

Bradford MM (1976). A rapid and sensitive method for the quantitation of microgram quantities of protein utilizing the principle of protein-dye binding. Anal Biochem 72: 248-254.

Brown V, Jin P, Ceman S, Darnell JC, O'Donnell WT, Tenenbaum SA et al (2001). Microarray identification of FMRP-associated brain mRNAs and altered mRNA translational profiles in fragile X syndrome. Cell 107: 477-487.

Carlberg I, Mannervik B (1985). Glutathione reductase. Methods Enzymol 113: 484-499.

Chauhan A, Chauhan V (2006). Oxidative stress in autism. Pathophysiology 13: 171-181.

Chiurazzi P, Neri G, Oostra BA (2003). Understanding the biological underpinnings of fragile $\mathrm{X}$ syndrome. Curr Opin Pediatr 15: 559-566.

Crusio WE, Schwegler H (1987). Hippocampal mossy fiber distribution covaries with open-field habituation in the mouse. Behav Brain Res 26: 153-158.
Dalle-Donne I, Giustarini D, Colombo R, Rossi R, Milzani A (2003). Protein carbonylation in human diseases. Trends Mol Med 9: 169-176.

Das S (1994). Vitamin E in the genesis and prevention of cancer. A review. Acta Oncol 33: 615-623.

De Diego Otero Y, Bakker CE, Raghoe P, Severijnen LWFM, Hoogeveen A, Oostra BA et al (2000). Immunocytochemical characterization of FMRP, FXR1 and FXR2 during embryonic development in the mouse. Gene Funct Dis 1: 28-37.

De Diego Otero Y, Severijnen LA, van Cappellen G, Schrier M, Oostra B, Willemsen R (2002). Transport of fragile X mental retardation protein via granules in neurites of PC12 cells. $\mathrm{Mol}$ Cell Biol 22: 8332-8341.

Dean RT, Fu S, Stocker R, Davies MJ (1997). Biochemistry and pathology of radical-mediated protein oxidation. Biochem J 324: $1-18$.

del Arco I, Muñoz R, Rodríguez De Fonseca F, Escudero L, MartínCalderón JL, Navarro $M$ et al (2000). Maternal exposure to the synthetic cannabinoid HU-210: effects on the endocrine and immune systems of the adult male offspring. Neuroimmunomodulation 7: 16-26.

Dölen G, Osterweil E, Rao BS, Smith GB, Auerbach BD, Chattarji S et al (2007). Correction of Fragile X Syndrome in Mice. Neuron 56: $955-962$.

Doussau F, Gasman S, Humeau Y, Vitiello F, Popoff M, Boquet P et al (2000). Rho-related GTPase is involved in $\mathrm{Ca}(2+)-$ dependent neurotransmitter exocytosis. J Biol Chem 275: 7764-7770.

el Bekay R, Romero-Zerbo Y, Decara J, Sanchez-Salido L, Del ArcoHerrera I, Rodríguez-de Fonseca F et al (2007). Enhanced markers of oxidative stress, altered antioxidants and NADPHoxidase activation in brains from Fragile X mental retardation 1deficient mice, a pathological model for Fragile X syndrome. Eur J Neurosci 26: 3169-3180.

Esterbauer H, Cheeseman KH (1990). Determination of aldehydic lipid peroxidation products: malonaldehyde and 4-hydroxynonenal. Methods Enzymol 186: 407-421.

Fariss MW, Zhang JG (2003). Vitamin E therapy in Parkinson's disease. Toxicology 189: 129-146.

Flohé L, Gunzler WA (1984). Assays of glutathione peroxidase. Methods Enzymol 105: 14-21.

Floyd RA, Carney JM (1992). Free radical damage to protein and DNA: mechanism involved and relevant observation on brain undergoing oxidative stress. Ann Neurol 32: S22-S27.

Frankland PW, Wang Y, Rosner B, Shimizu T, Balleine BW, Dykens EM et al (2004). Sensorimotor gating abnormalities in young males with fragile $\mathrm{X}$ syndrome and Fmr1-knockout mice. Mol Psychiatry 9: 417-425.

Grossman AW, Elisseou NM, McKinney BC, Greenough WT (2006). Hippocampal pyramidal cells in adult Fmr1 knockout mice exhibit an immature-appearing profile of dendritic spines. Brain Res 1084: 158-164.

Gruss M, Braun K (2004). Age- and region-specific imbalances of basal amino acids and monoamine metabolism in limbic regions of female Fmr1 knock-out mice. Neurochem Int 45: 81-88.

Guo L, Wang LH, Sun B, Yang JY, Zhao YQ, Dong YX et al (2007). Direct in vivo evidence of protective effects of grape seed procyanidin fractions and other antioxidants against ethanolinduced oxidative DNA damage in mouse brain cells. J Agric Food Chem 55: 5881-5891.

Hagerman R, Hagerman P (2001). Fragile X syndrome: a model of gene-brain-behavior relationships. Mol Genet Metab 74: 89-97.

Hayashi ML (2007). Inhibition of p21-activated kinase rescues symptoms of fragile X syndrome in mice. Proc Natl Acad Sci USA 104: 11489-11494.

Herman JP, Cullinan WE (1997). Neurocircuitry of stress: central control of the hypothalamo-pituitary-adrenocortical axis. Trends Neurosci 20: 78-84. 
Hessl D, Glaser B, Dyer-Friedman J, Blasey C, Hastie T, Gunnar M et al (2002). Cortisol and behavior in fragile $\mathrm{X}$ syndrome. Psychoneuroendocrinology 27: 855-872.

Hissin PJ, Hilf R (1976). A fluorometric method for determination of oxidized and reduced glutathione in tissues. Anal Biochem 74: 214-226.

Hovatta I, Tennant RS, Helton R, Marr RA, Singer O, Redwine JM et al (2005). Glyoxalase 1 and glutathione reductase 1 regulate anxiety in mice. Nature 438: 662-666.

Iannello RC, Crack PJ, de Haan JB, Kola I (1999). Oxidative stress and neural dysfunction in Down syndrome. J Neural Transm 57: 257-267.

Lambeth JD (2004). Nox enzymes and the biology of reactive oxygen. Nat Rev Immunol 4: 181-189.

Lauterborn JC, Rex CS, Kramár E, Chen LY, Pandyarajan V, Lynch $\mathrm{G}$ et al (2007). Brain-derived neurotrophic factor rescues synaptic plasticity in a mouse model of fragile $\mathrm{X}$ syndrome. J Neurosci 27: 10685-10694.

Lee A, Li W, Xu K, Bogert BA, Su K, Gao FB (2003). Control of dendritic development by the Drosophila fragile X-related gene involves the small GTPase Rac1. Development 130: 5543-5552.

Levine RL (2002). Carbonyl modified proteins in cellular regulation, aging, and disease. Free Radic Biol Med 32: 790-796.

Li Q, Ho CS, Marinescu V, Bhatti H, Bokoch GM, Ernst SA et al (2003). Facilitation of $\mathrm{Ca}(2+)$-dependent exocytosis by Rac1GTPase in bovine chromaffin cells. J Physiol 550: 431-445.

Li Y, Zhu H, Kuppusamy P, Roubaud V, Zweier JL, Trush MA (1998). Validation of lucigenin (bis- $N$-methylacridinium) as a chemilumigenic probe for detecting superoxide anion radical production by enzymatic and cellular systems. J Biol Chem 273: 2015-2023.

Lister RG (1987). The use of a plus-maze to measure anxiety in the mouse. Psychopharmacology Berl 92: 180-185.

Liu J, Wang X, Shigenaga MK, Yeo HC, Mori A, Ames BN (1996). Immobilization stress causes oxidative damage to lipid, protein and DNA in the brain of rats. FASEB J 10: 1532-1538.

Magarinos AM, McEwen BS (1995). Stress-induced atrophy of apical dendrites of hippocampal CA3c neurons: involvement of glucocorticoid secretion and excitatory amino acid receptors. Neuroscience 69: 89-98.

Martinez LA, Klann E, Tejada-Simon MV (2007). Translocation and activation of Rac in the hippocampus during associative contextual fear learning. Neurobiol Learn Mem 88: 104-113.

McBride SM, Choi CH, Wang Y, Liebelt D, Braunstein E, Ferreiro D et al (2005). Pharmacological rescue of synaptic plasticity, courtship behavior, and mushroom body defects in a Drosophila model of fragile X syndrome. Neuron 45: 753-764.

McEwen BS (2007). Physiology and neurobiology of stress and adaptation: central role of the brain. Physiol Rev 87: 873-904.

Miyashiro KY, Beckel-Mitchener A, Purk TP, Becker KG, Barret T, Liu L et al (2003). RNA cargoes associating with FMRP reveal deficits in cellular functioning in Fmr1 null mice. Neuron 37: 417-431.

Morris MC, Evans DA, Bienias JL, Tangney CC, Bennett DA, Aggarwal N et al (2002). Dietary intake of antioxidant nutrients and the risk of incident Alzheimer disease in a biracial community study. JAMA 287: 3230-3237.

Osakada F, Hashino A, Kume T, Katsuki H, Kaneko S, Akaike A (2003). Neuroprotective effects of alpha-tocopherol on oxidative stress in rat striatal cultures. Eur J Pharmacol 465: $15-22$.
Peier AM, McIlwain KL, Kenneson A, Warren ST, Paylor R, Nelson DL (2000). (Over)correction of FMR1 deficiency with YAC transgenics: behavioral and physical features. Hum Mol Genet 9: 1145-1159.

Phillips RG, LeDoux JE (1992). Differential contribution and amygdala and hippocampus to cued and contextual fear conditioning. Behav Neurosci 106: 274-285.

Sano M, Ernesto C, Thomas RG, Klauber MR, Schafer K, Grundman $M$ et al (1997). A controlled trial of selegiline, alpha-tocopherol, or both as treatment for Alzheimer's disease. The Alzheimer's Disease Cooperative Study. N Engl J Med 336: 1216-1222.

Singh LK, Pang X, Alexacos N, Netaumen R, Theoharides C (1993). Acute immobilization stress triggers skin mast cell degranulation via corticotropin releasing hormone neurotension and substance link to neurogenic skin disorders. Brain Behav Immun 13: 225-239.

Sundaresan M, Yu ZX, Ferrans VJ, Sulciner DJ, Gutkind JS, Irani K et al (1996). Regulation of reactive-oxygen-species generation in fibroblasts by Rac1. Biochem J 318: 379-382.

Verkerk AJ, Pieretti M, Sutcliffe JS, Fu YH, Kuhl DP, Pizzuti A et al (1991). Identification of a gene (FMR-1) containing a CGG repeat coincident with a breakpoint cluster region exhibiting length variation in fragile X syndrome. Cell 65: 905-914.

Virgin Jr CE, Ha TP, Packan DR, Tombaugh GC, Yang SH, Horner HC et al (1991). Glucocorticoids inhibit glucose transport and glutamate uptake in hippocampal astrocytes: implications for glucocorticoid neurotoxicity. J Neurochem 57: 1422-1428.

Ward NE, Pierce DS, Chung SE, Gravitt KR, O’Brian CA (1998). Irreversible inactivation of protein kinase $\mathrm{C}$ by glutathione. J Biol Chem 273: 12558-12566.

Warholm M, Guthenberg C, von Bahr C, Mannervik B (1985). Glutathione transferases from human liver. Methods Enzymol 113: 499-504.

Wautier MP, Chappey O, Corda S, Stern DM, Schmidt AM, Wautier JL (2001). Activation of NADPH oxidase by AGE links oxidant stress to altered gene expression via RAGE. Am J Physiol Endocrinol Metab 280: E685-E694.

Weber GF (1999). Final common pathways in neurodegenerative diseases: regulatory role of the glutathione cycle. Neurosci Biobehav Rev 23: 1079-1086.

Weiler IJ, Irwin SA, Klintsova AY, Spencer CM, Brazelton AD, Miyashiro K et al (1997). Fragile X mental retardation protein is translated near synapses in response to neurotransmitter activation. Proc Natl Acad Sci USA 94: 5395-5400.

Wiens KM, Lin H, Liao D (2005). Racl induces the clustering of AMPA receptors during spinogenesis. J Neurosci 25: 1062710636.

Yan CY, Greene LA (1998). Prevention of PC12 cell death by NAC requires activation of the Ras pathway. I Neurosci 18: 4042-91998.

Yan QJ, Rammal M, Tranfaglia M, Bauchwitz RP (2005). Suppression of two major fragile $\mathrm{X}$ syndrome mouse model phenotypes by the mGluR5 antagonist MPEP. Neuropharmacology 49: 1053-1066.

Zalfa F, Eleuteri B, Dickson KS, Mercaldo V, De Rubeis S, di Penta $\mathrm{A}$ et al (2007). A new function for the fragile $\mathrm{X}$ mental retardation protein in regulation of PSD-95 mRNA stability. Nat Neurosci 10: 578-587.

Zingg JM, Azzi A (2004). Non-antioxidant activities of vitamin E. Curr Med Chem 11: 1113-1133.

Supplementary Information accompanies the paper on the Neuropsychopharmacology website (http://www.nature.com/npp) 